\title{
Systems engineering and design of a Mars Polar Research Base with a human \\ crew
}

\author{
Anne-Marlene Rüede ${ }^{\mathrm{a}, \mathrm{c}, *}$, Anton Ivanov ${ }^{\mathrm{b}, \mathrm{c}}$, Claudio Leonardi ${ }^{\mathrm{d}, \mathrm{c}}$, Tatiana Volkova ${ }^{\mathrm{e}}$ \\ ${ }^{a}$ Department of Architecture (ENAC)/Space Engineering Center (eSpace), Ecole Polytechnique Fédérale de Lausanne (EPFL), Route Cantonale, 1015, Lausanne, \\ Switzerland \\ ${ }^{\mathrm{b}}$ Space Engineering Center (eSpace), Ecole Polytechnique Fédérale de Lausanne (EPFL), Route Cantonale, 1015, Lausanne, Switzerland \\ ${ }^{\mathrm{c}}$ Space Center, Skolkovo Institute of Science and Technology, 3 Nobel str, Moscow, Russia \\ ${ }^{\mathrm{d}}$ Informatics and Visualization Laboratory (LIV), Clip-Air Project, Ecole Polytechnique Fédérale de Lausanne (EPFL), Route Cantonale, 1015, Lausanne, Switzerland \\ ${ }^{\mathrm{e}}$ EDCE Doctoral Program/Swiss Space Center, Ecole Polytechnique Fédérale de Lausanne (EPFL), Route Cantonale, 1015, Lausanne, Switzerland
}

\section{A R T I C L E I N F O}

\section{Keywords:}

Mars

Polar layered deposits

Human exploration

Research base

In-situ resource utilization

Mission architecture

\begin{abstract}
A B S T R A C T
Mars Polar Ice caps have been known ever since they were first observed by Cassini. Robotic exploration missions, starting with Mariner 9, have confirmed that they are composed of water ice. During later missions, instruments such as Mars Global Surveyor's MOLA have established a detailed topography and have estimated their depth at about $3 \mathrm{~km}$ in the thickest part, while detailed internal structure has been investigated by MARSIS from Mars Express and SHARAD from the Mars Reconnaissance Orbiter. This analysis proposes to establish a base near North Polar Layered Deposits to investigate Mars' climate, hydrological processes and to test for possible traces of life. The objectives of the mission are to sustain a crew for nine months on the surface of Mars, near the North Pole, and to bring the crew back to Earth safely. During the surface mission, the crew will drill and analyze Polar Layered Deposits in ice samples. Furthermore, because the North Polar region provides an easy access to water ice, this area has the potential of sustaining a long-term human presence. The Mars Polar Research mission shall therefore prepare for long term missions, spanning over multiple crew generations. Indeed, longer duration missions and larger crews should be facilitated by this first mission. This paper describes a mission design for a Mars Polar Research base using systems engineering approach and scenario testing. The goal of the work is to establish a strategy composed of various technologies that have been selected accordingly. The requirements related to crew composition, human physiology and psychology adaptation, quality of communication, challenges and prospects of advancing science, as well as optimum habitat design and its usability, are derived and compiled into mass, volume, data and power consumption. A design for the base and mission scenario is also proposed. Given the identified requirements, possible technologies for life support systems, radiation protection, in-situ propellant production, thermal control, air pressure difference compensation and availability of power are discussed and solutions to focus on are recommended. Furthermore, the requirements for a long-term mission preparation are also identified and solutions to include in a first Mars mission with crew are recommended. In conclusion, approximately 110 metric tons and $160 \mathrm{~kW}$ are required to enable a Mars Polar mission with a human crew. A two-phase mission is recommended for enabling the testing of key in-situ resource utilization technologies allowing to minimize mass, while ensuring the security of the crew. The use of optimal payload and fairing, a Mars orbit crane system and deployable structures are recommended. Finally, in preparation for a long-term presence of humans on Mars, including in-situ testing of key technologies enabling the production of consumables facilitating autonomy from Earth is suggested. The consumables that have been identified as not being able to be tested before a first crew is sent to Mars are food and energy production. These developments may serve as priorities for current Mars settlement programs.
\end{abstract}

\footnotetext{
* Corresponding author. Space Engineering Center (eSpace), Ecole Polytechnique Fédérale de Lausanne (EPFL), Route Cantonale, 1015, Lausanne, Switzerland.

E-mail addresses: anne-marlene.ruede@epfl.ch (A.-M. Rüede), anton.ivanov@epfl.ch (A. Ivanov), claudio.leonardi@epfl.ch (C. Leonardi), tatiana.volkova@epfl.ch (T. Volkova).
} 


\author{
Nomenclature \\ $\mathrm{I}_{\mathrm{sp}} \quad$ specific impulse $[s]$ \\ Acronyms \\ ALARA As Low as Reasonably Achievable \\ ALICE ALuminium ICE rocket propellant \\ CGR Cosmic Galactic Radiation \\ CME Coronal Mass Ejection \\ ECLSS Environmental Control and Life Support System \\ GTO Geostationary Transfer Orbit \\ HDO Deuterated Water \\ IRVE-3 Inflatable Reentry Vehicle Experiment \\ ISPP In-situ Propellant Production
}

ISRU In-situ Resource Utilization

ISS International Space Station

LUS Large Upper Stage

MEPAG Mars Exploration Program Analysis Group

MSL Mars Science Laboratory

NASA National Aeronautics and Space Administration

PLD Polar Layered Deposits

RAD Radiation Assessment Detector

RTG Radioisotope Thermoelectric Generator

RWGS Reverse Water-Gas Shift

SLS Space Launch System

SPE Solar Particle Event

TRL Technology Readiness Level

\section{Introduction}

In 1995, the first exoplanet has been discovered and numerous other exoplanets, including in habitable zones, have been discovered since $[1,2]$. However, even in our own solar system, we do not have any conclusive proof if life has developed on other planets or satellites. Since the 16th century, theories about life on Mars have been advanced, however, they were put in doubt with the beginning of space exploration in the 20th century, after the first images of Mariner 7 showed that there were no observable features in accordance with the theories of intelligent life on Mars [3]. Despite initially seeming lifeless, the latest research from Mars orbiters [4] and rovers [5] suggests an abundance of water related processes in the past on Mars, which is an indirect argument that life may have existed once on Mars [6,7].

If life or traces of life are still to be found on Mars, a likely place for them to be found is in the Polar Layered Deposits (PLD) at the Martian North and South Poles. Therefore, in an effort to verify or exclude if life is or was present elsewhere in the Solar System, a mission to a Mars Polar region is required.

Furthermore, Mars Polar missions are also required in the search for the history of Mars' formation and evolution. Understanding the history of Mars could prove to be a key knowledge in the understanding of our own planet, as the exact mechanisms that have driven Mars to loose its atmosphere and its water to recede into polar caps still need to be further researched [8] and similar phenomena might be happening on Earth.

This paper proposes a systems engineering solution for a nine month mission with a human crew on the North Pole of Mars. It investigates technical and human requirements and proposes a strategy using in-situ resources to minimize the mission mass. The conceptual design of a Mars Polar Research Mission, illustrated in Fig. 1, is also proposed, along with a scenario validation of the concept. A budget estimates mass, volume, data and power consumption. Finally, the limits to autonomy are identified and discussed for a first generation mission and in the effort for a long-term human presence. Areas in which technologies are still to be developed to enable crewed Polar Mars missions are also identified and discussed.

\section{Mission definition}

\subsection{Objectives}

The Mars Exploration Program Analysis Group (MEPAG) [9] of the National Aeronautics and Space Administration (NASA) has established the scientific goals for the exploration of Mars for the coming years. These goals are the following:

- Determine if Mars ever supported life
- Understand the processes and history of climate on Mars

- Understand the origin and evolution of Mars as a geological system - Prepare for human exploration

These goals are divided into objectives and all four goals possess objectives that require the drilling and analysis of North Polar Layered Deposits (PLD). Indeed, the Polar caps are high-priority candidates in the research for past or present traces of life on Mars. Furthermore, the ice in the caps is estimated to be several millions of years old [10] and because the layered deposits are formed by layers of water ice and dust, they hold records of Mars' formation, climate and hydrological systems. Finally, the Northern regions are a good candidate in preparing for the long-term presence of humans on Mars, as the ice cap is a water reservoir, which can be utilized for producing water for the crew, food and in-situ produced propellant.

\subsection{Outline}

The Mars Polar Research Mission is defined as a 288-day crewed surface mission near the North Pole of Mars. The duration corresponds to the time during which the Pole is exposed to constant sunlight and the Polar caps are exposed to atmosphere [11], facilitating in-situ work. The crew will be monitoring rovers drilling in Polar Layered Deposits (PLD) and then analyze the samples. Furthermore, the crew will also conduct experiments required to enable preparations for a long-term presence of humans on the planet.

Because of the complexity of the mission, the need for human experts to analyze the Polar Layered Deposits (PLD) and to adapt the scientific mission in accordance with the results of the analysis, the crew is composed of a team of six men and women with the following expertises and cross training in all other mentioned fields:

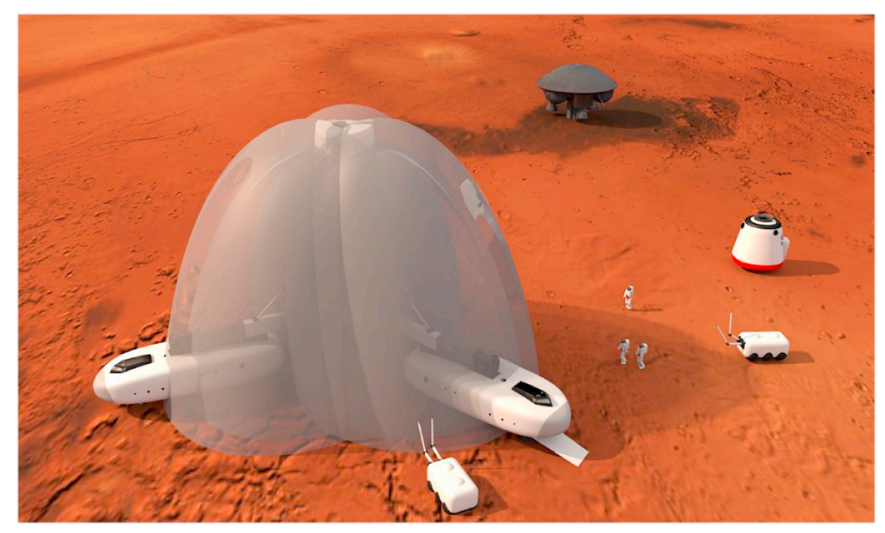

Fig. 1. Artist's view of the base. 
- Piloting \& navigation

- Electrical \& communication engineering

- Mechanical engineering

- Medicine, dentistry \& psychology

- Geology \& data processing

- Biology \& botany

\section{Design strategy}

In this section, the design constraints near the North Pole of Mars are identified, possible solutions are examined, compared and finally, a solution which will be integrated into the design of the base is selected.

\subsection{Habitat deployment strategy}

Mars has a variety of in-situ resources that can be used to build a habitat, decreasing the mass and volume required to be sent from Earth. Core elements, systems and tools need to be brought from Earth but the materials required to build the shell of the habitat and ensure the production of consumables can potentially be processed from local resources.

There are different scenario outlines, which can be selected for Mars bound missions with a human crew. The first option is not using any locally available resources. The completed habitat must therefore be brought from Earth. The base could be a hard shell or use inflatable elements. The second option is for the crew to build additional modules upon arrival from in-situ resources. The third option is for the habitat to be built before the crew is sent to Mars, which allows the use of in-situ resources to the fullest extent possible.

According to Table 1, the third strategy has been selected for this mission. Indeed, mass can be minimized when using in-situ resources and the security of the crew is increased, considering that the payload capacity to Geostationary Transfer Orbit (GTO) is currently limited to $14,210 \mathrm{~kg}$ with the Delta Heavy rocket [12]. According to NASA's Technology Roadmap [13], the utilization of in-situ resources is desirable as it could facilitate Mars crewed missions, especially when considering consumable resources such as resources serving life support, and it could also allow for more payload mass to be dedicated to crew and science. However, in-situ resource utilization has never been tested on Mars.

\subsection{Resources on Mars}

Table 2 shows that Mars has a variety of resources that can be utilized for constructing a base for a crew, especially in the North Polar region, where large reservoirs of ice could ensure access to water and therefore possibly enable long-term missions.

The resources found on Mars can be either used in their natural state, undergo simple processing such as compression or 3D printing or can be heavily processed. The latter implies recombining elements

Table 1

This table compares habitat deployment strategy options for 288-day Mars crewed surface missions, according to alternative solutions investigated during the systems engineering and design of the Mars Polar Research Mission. Each option is given a mark from 1 to 3 for each criteria, 3 being the most satisfying.

\begin{tabular}{llll}
\hline & Option 1 & Option 2 & Option 3 \\
\hline number of launches & 1 & 1 & 3 \\
orbital assemblies & 1 & 1 & 1 \\
Landing & 2 & 2 & 1 \\
ease of deployment & 2 & 2 & 1 \\
safety of the crew & 1 & 1 & 3 \\
future evolution & 1 & 2 & 3 \\
total mass/cost & 1 & 2 & 3 \\
\hline total & 9 & 11 & 15
\end{tabular}

Table 2

This table lists the values representing relative mass abundance of chemical elements expressed as the most common oxide for the Martian soil (from Out of this World: The New Field of Space Architecture [14]). For the atmosphere, the values represent relative volume abundance of chemical elements expressed as its most common oxide (from The composition of the atmosphere at the surface of Mars [15]) and information on the Polar Caps (from Strong Water Isotopic Anomalies in the Martian Atmosphere: Probing Current and Ancient Reservoirs [11]).

\begin{tabular}{llllll}
\hline Martian Soil & \multicolumn{3}{c}{ Atmosphere } & \multicolumn{3}{c}{ Polar Ice } \\
\hline constituents & $\%$ & constituents & $\%$ & constituents & $\%$ \\
\hline $\mathrm{SiO}_{2}$ & 43.8 & $\mathrm{CO}_{2}$ & 95.32 & $\mathrm{H}_{2} \mathrm{O}$ & $99.7 \%$ \\
$\mathrm{Fe}_{2} \mathrm{O}_{3}$ & 18.2 & $\mathrm{~N}_{2}$ & 2.7 & $\mathrm{HDO}^{\mathrm{a}}$ & $0.25 \%$ \\
$\mathrm{Al}_{2} \mathrm{O}_{3}$ & 7.2 & $\mathrm{Ar}$ & 1.6 & $\mathrm{CO}_{2}$ & only in winter \\
$\mathrm{SO}_{3}$ & 7.2 & $\mathrm{O}_{2}$ & 0.13 & & \\
$\mathrm{MgO}$ & 6.0 & $\mathrm{CO}$ & 0.07 & & \\
$\mathrm{CaO}$ & 5.8 & $\mathrm{H}_{2} \mathrm{O}$ & 0.03 & & \\
$\mathrm{Na} \mathrm{N}_{2} \mathrm{O}$ & 1.34 & $\mathrm{NO}$ & 0.013 & & \\
$\mathrm{Cl}$ & 0.8 & $\mathrm{Ne}$ & traces & & \\
$\mathrm{P}_{2} \mathrm{O}_{5}$ & 0.68 & $\mathrm{Kr}$ & traces & & \\
$\mathrm{TiO}_{2}$ & 0.6 & $\mathrm{Xe}$ & traces & & \\
$\mathrm{MnO}_{2}$ & 0.45 & $\mathrm{O}_{3}$ & traces & & \\
$\mathrm{Cr}_{2} \mathrm{O}$ & 0.29 & & & & \\
$\mathrm{~K}_{2} \mathrm{O}$ & 0.10 & & & & \\
\hline
\end{tabular}

${ }^{\text {a }}$ Deuterated Water.

found on Mars to produce materials not naturally found on the planet. Heavy processing can also recombine in-situ elements with other elements brought from Earth and therefore, a wide variety of materials can be produced. Table 3 gives an overview of the different materials than could be produced on Mars, while describing their origin.

\subsection{Life support system}

In order to sustain a crew on any mission, vital consumbles must be available at all times. These include air (oxygen and nitrogen), food and water. On short Earth orbiting missions, consumables are usually prepared in advance and are stored until consumption [17]. However, on longer missions, it becomes interesting to compare resources brought from Earth to in-situ produced resources. This is especially true for destinations such as the planet Mars, that have in-situ resources that could partially cover the requirements in consumables for a mission with crew and therefore reduce the mass of the mission.

Crew size, mission duration, payload capacity and availability of insitu resources are driving factors in the establishment of a strategy for a life support system and the determination of the fraction of consumables that are prepared in advance, in-situ produced and recycled. Furthermore, cost, risk, system and technology availability and readiness and safety analysis also drive and limit the strategy.

It is necessary to bring from Earth all resources that cannot be guaranteed in-situ, as consumables are life critical. On Mars, it is possible to produce water, oxygen and nitrogen. Food and energy, however, cannot be produced in-situ during a first generation Mars mission. Having selected a two phase mission allows for water, oxygen and possibly nitrogen, if required, to be produced in-situ before the crew is sent from Earth. Furthermore, these elements can also be used during the first phase for deployment and pressurization of the habitat.

However, a life support system comparable to the Environmental Control and Life Support System (ECLSS) on the International Space Station (ISS) must be included in the mission payload, as the most efficient strategy to limit the required input of resources into a base is to recycle the resources. ISRU is used whenever possible to produce the initial resources required for a closed-loop system and to compensate for leakage, which cannot be completely avoided. All resources which cannot be guaranteed by in-situ resource utilization (ISRU) will need to be brought from Earth. 
Table 3

This table gives an overview of the different materials that can be manufactured on Mars. The columns describe which constituents origin from Mars or from Earth. In the case of Mars locally found resources, it is determined if it originates from the Martian soil, atmosphere or mined Polar ice [16].

\begin{tabular}{|c|c|c|}
\hline Material & Mars & Earth \\
\hline \multicolumn{3}{|l|}{ construction materials } \\
\hline bricks & soil, $\mathrm{H}_{2} \mathrm{O}^{*}, \dagger,+$ & - \\
\hline mortar & soil, $\mathrm{H}_{2} \mathrm{O}^{*}, \dagger,+$ & - \\
\hline "duricrete" imitation & soil, $\mathrm{H}_{2} \mathrm{O}^{*}, \dagger,+$ & - \\
\hline ice & $\mathrm{H}_{2} \mathrm{O} \leftarrow$ & - \\
\hline $\begin{array}{l}\text { polyethylene "pykrete" } \\
\text { glasses \& ceramics }\end{array}$ & glasses \& ceramics & - \\
\hline glass (black or clear) & $\mathrm{SiO}_{2}^{*}$ & - \\
\hline \multicolumn{3}{|l|}{ plastics } \\
\hline ethylene based plastics (1) & $\mathrm{CO}_{2} \dagger, \mathrm{H} \dagger,+$ & - \\
\hline $\begin{array}{l}\text { ethylene based plastics ( } 2 \text { ) } \\
\text { metals }\end{array}$ & $\mathrm{CO}_{2}$ & $\mathrm{H}$ \\
\hline steel & $\mathrm{Fe}_{2} \mathrm{O}_{3} *, \mathrm{Mn}^{*}, \mathrm{P}^{*}, \mathrm{Si}^{*}, \mathrm{C} \dagger$ & - \\
\hline aluminum & $\mathrm{Al}_{2} \mathrm{O}_{3} *$ & - \\
\hline silicon & $\mathrm{SiO}_{2}{ }^{*}, \mathrm{C} \dagger$ & - \\
\hline \multicolumn{3}{|l|}{ biological support } \\
\hline food & soil, $\mathrm{CO}_{2} \dagger, \mathrm{u}$. & seeds, $\mathrm{u}$. \\
\hline water (1) & $\mathrm{H}_{2} \mathrm{O}^{*}, \uparrow,+$ & - \\
\hline water (2) & $\mathrm{CO}_{2} \dagger$ & $\mathrm{H}$ \\
\hline oxygen (1) & $\mathrm{H}_{2} \mathrm{O} \dagger,+$ & - \\
\hline oxygen (2) & $\mathrm{CO}_{2}^{\dagger}$ & - \\
\hline nitrogen & $\mathrm{N}_{2} \dagger$ & - \\
\hline \multicolumn{3}{|l|}{ propellants } \\
\hline hydrogen & $\mathrm{H} \dagger,+$ & - \\
\hline carbon monoxide & $\mathrm{CO}_{2} \dagger$ & - \\
\hline methane (1) & $\mathrm{CO}_{2} \dagger, \mathrm{H} \dagger,+$ & - \\
\hline methane (2) & $\mathrm{CO}_{2}$ & $\mathrm{H}$ \\
\hline methanol (1) & $\mathrm{CO}_{2} \dagger, \mathrm{H} \dagger,+$ & - \\
\hline methanol (2) & $\mathrm{CO}_{2}$ & $\mathrm{H}$ \\
\hline ethylene (1) & $\mathrm{CO}_{2} \dagger, \mathrm{H} \dagger,+$ & - \\
\hline ethylene (2) & $\mathrm{CO}_{2}$ & $\mathrm{H}$ \\
\hline ALICE & $\mathrm{H}_{2} \mathrm{O} \leftarrow, \mathrm{Al}^{*}$ & - \\
\hline
\end{tabular}

* Martian soil, $\dagger$ atmosphere, $\uparrow$ mined Polar ice, u unknown, (1) option 1, (2) option 2.

\subsection{Propellant}

Propellant accounts for the majority of the total mass of the mission. Furthermore, because rockets only have a limited payload capacity, trips between the surface of a planet and its orbit must be multiplied, spending even more propellant on the rocket's structure rather than on the payload itself. A possible solution to limit the requirements in propellant is the availability of a crane system [18].

Indeed, a crane vehicle could utilize in-situ produced propellant (ISPP) and therefore eliminate the need to bring propellant for Mars surface-to-orbit transfers. Attaching various payloads would be possible with a modular crane vehicle. With such a crane system, the mission mass could be reduced, especially when considering the possibility of several crew generations visiting Mars. Two fueled vehicles for redundancy have been considered to be available in Mars orbit at the time of the launch of the first payloads of the Mars Polar Research Mission. The crane system could also be used for unrelated Mars missions, facilitating the human and robotic exploration of Mars.

Different Mars surface in-situ propellant production (ISPP) methods have been evaluated and compared in Table 4. Factors taken into account are efficiency $\left(\mathrm{I}_{\mathrm{sp}}\right)$, equipment convenience (mass and volume), power consumption, simplicity of production, reliability, availability, and possible benefits on other systems for the habitat, such as radiation protection for example.

Three options stand out for a crewed mission to the Martian North Pole. These are methane oxide, ethylene oxide and ALICE. Methane and ethylene can both be produced using the Reverse Water-Gas Shift reaction (RWGS) while ALICE is a combination of water ice and nano-
Table 4

This table compares propellant options for the Polar regions following criteria that are relevant for a Mars mission with crew. Each option is given a mark from 1 to 3 for each criteria, 3 being the most satisfying [19-25].

\begin{tabular}{llllll}
\hline & $\begin{array}{l}\text { Carbon } \\
\text { Monoxide } \\
\text { \& Oxygen }\end{array}$ & $\begin{array}{l}\text { Methane } \\
\text { \& Oxygen }\end{array}$ & $\begin{array}{l}\text { Methanol } \\
\text { \& Oxygen }\end{array}$ & $\begin{array}{l}\text { Ethylene } \\
\text { \& Oxygen }\end{array}$ & ALICE \\
\hline efficiency ( $\mathrm{I}_{\mathrm{sp}}$ ) & 1 & 2 & 3 & 3 & 3 \\
equipment & 1 & 2 & 2 & 2 & 3 \\
power consumption & 1 & 2 & 3 & 3 & 1 \\
production & 1 & 3 & 1 & 3 & 2 \\
reliability & 1 & 2 & 2 & 2 & 3 \\
availability & 3 & 2 & 2 & 2 & 1 \\
versatility & 2 & 2 & 1 & 3 & 2 \\
\hline total & 10 & 15 & 14 & 18 & 15 \\
\hline
\end{tabular}

aluminum powder. For the Mars Polar Research Mission, ethylene has been selected as propellant, as it presents advantages such as requiring only small quantities of hydrogen and a fraction of the energy to produce compared to methane and ALICE. It can also be used to produce polyethylene and other derivatives, which is particularly useful for long-term missions. Furthermore, ALICE has the disadvantage of requiring large volumes of ice to be mined and the production of aluminum, which is a difficult task on Mars.

\subsection{Radiation protection}

In 2012, NASA launched its Mars Science Laboratory mission (MSL) to Mars. The rover, Curiosity, was equipped with a Radiation Assessment Detector (RAD) that recorded the incoming dose of radiation during both the travel to and its stay on Mars. The RAD has identified two main types of radiation, which astronauts must be protected from. The first type is Cosmic Galactic Radiation (CGR) and the second is Solar Particle Events (SPE). The first is a type of constant radiation in the Universe, which could originate from supernova remnants. The second type originates from the Sun and is a consequence of Coronal Mass Ejections (CME). SPE radiation is more energetic than CGR and can potentially be lethal to astronauts within a short time frame while GCR increases the risk of fatal cancers over time. On the contrary to CGR, which is constant, high levels of SPE radiation only occur punctually.

The measurements of the RAD indicate that an astronaut would be exposed to a Cosmic Galactic Radiation (CGR) dose equivalent to about $131.4 \mathrm{mSv}$ per trip during a nine month transit between Earth and Mars and to $184.32 \mathrm{mSV}$ for a 288-day surface mission on Mars [26]. This amounts to a total estimated radiation of $447.12 \mathrm{mSv}$ in a 835-day interval. This result is problematic considering that NASA guidelines stipulate that the exposure limit during an astronauts career should not increase the risk of cancer by more than $3 \%$, which corresponds to an annual dose of $500 \mathrm{mSv}$ considering an average of crew members of all genders and ages. In the case of 25 year old females, who are the most sensitive to radiation, a career dose of $400 \mathrm{mSv}$ is the maximum admissible dose under NASA guidelines [27].

Considering this, shielding to protect from radiation should be included in the design of a Mars Polar Research Base. Because shielding is difficult and not required by law, NASA guidelines for radiation exposure are As Low as Reasonably Achievable (ALARA) and the results of the RAD measurements indicate that these guidelines should be applied in this mission, especially when considering the possibility of the habitat serving for a long-term mission during which astronauts could stay on Mars for longer periods of time [29-31,28].

The exposure to CGR can be reduced with the right choice of shielding. Therefore, different materials have been identified as possible protection against CGR. Fig. 2 compares the shielding efficiency of 


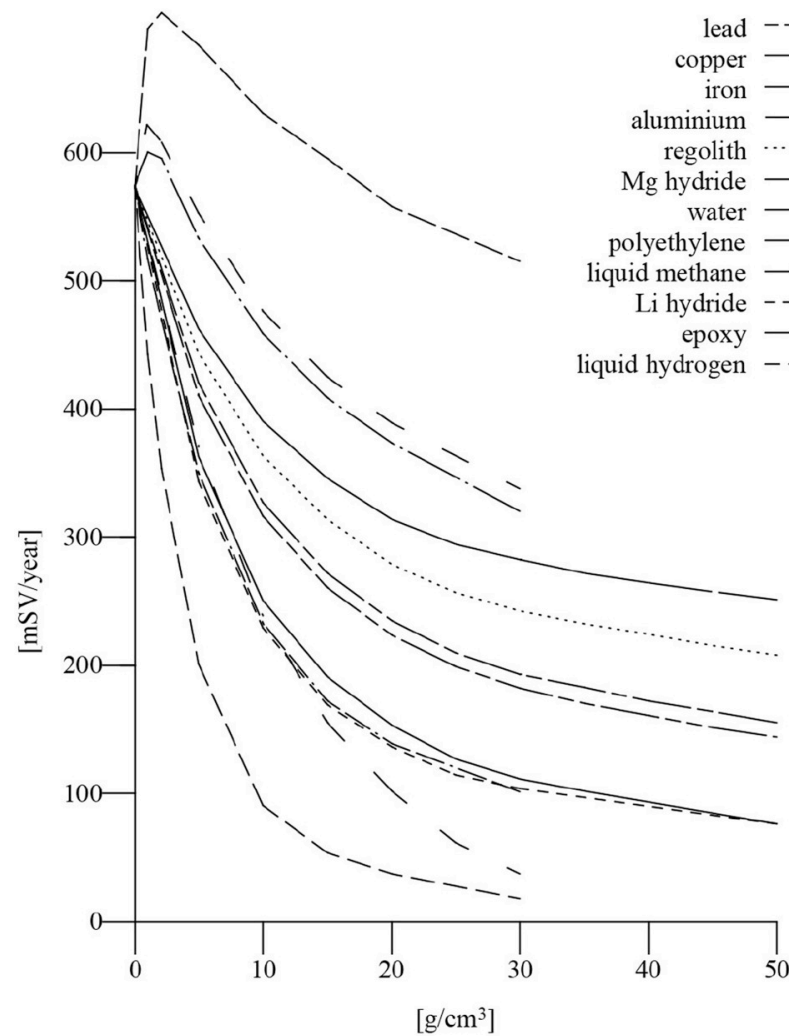

Fig. 2. This graph compares the radiation dose which accrues during a year behind specific mass $\left(\mathrm{g} / \mathrm{cm}^{2}\right)$. This figure combines results of studies in Radiation Effects and Shielding Requirements in Human Missions to the Moon and Mars [27] and Shielding Strategies for Human Space Exploration [28].

candidate materials that could be used as crew protection in the Mars habitat. Some materials that are available on Mars or can be easily produced from in-situ resources are good candidates for radiation shielding. Furthermore, some of these materials are the same as those that have also been identified as possible propellant options, such as liquid methane, water or polyethylene, which is a derivative of ethylene.

As for SPE radiation, the method currently used to protect a crew against it is for the astronauts to take shelter in airlocks until the radiation comes back to safe levels. This usually takes a day or two and it is possible to warn the crew shortly before the radiation levels become dangerous, as an event can be observed before the radiation has reached the spacecraft or Mars. Ideally, the mission would take place during a period of solar minima during which SPEs are rarer and less energetic [32,33].

\subsection{Power}

According to Table 5, the power requirements of the mission are estimated at about $160 \mathrm{~kW}$ over an overall period of minimum ten years. However, each phase of the mission has its own power requirement and the multiple launches required imply the use of several smaller power sources. The first phase requires about $110 \mathrm{~kW}$ over a span of about ten years, while the second phase requires only about $50 \mathrm{~kW}$ over a minimum of five years for one mission.

According to Fig. 3, nuclear reactors, photovoltaic panels, solar dynamic (solar concentrators) and radioisotope thermoelectric generators (RTG) can be considered as suitable power sources.

Because of the length of the mission and its location at the North Pole, which implies little but constant light and then complete darkness during half a Martian year, photovoltaic panels are not a suitable

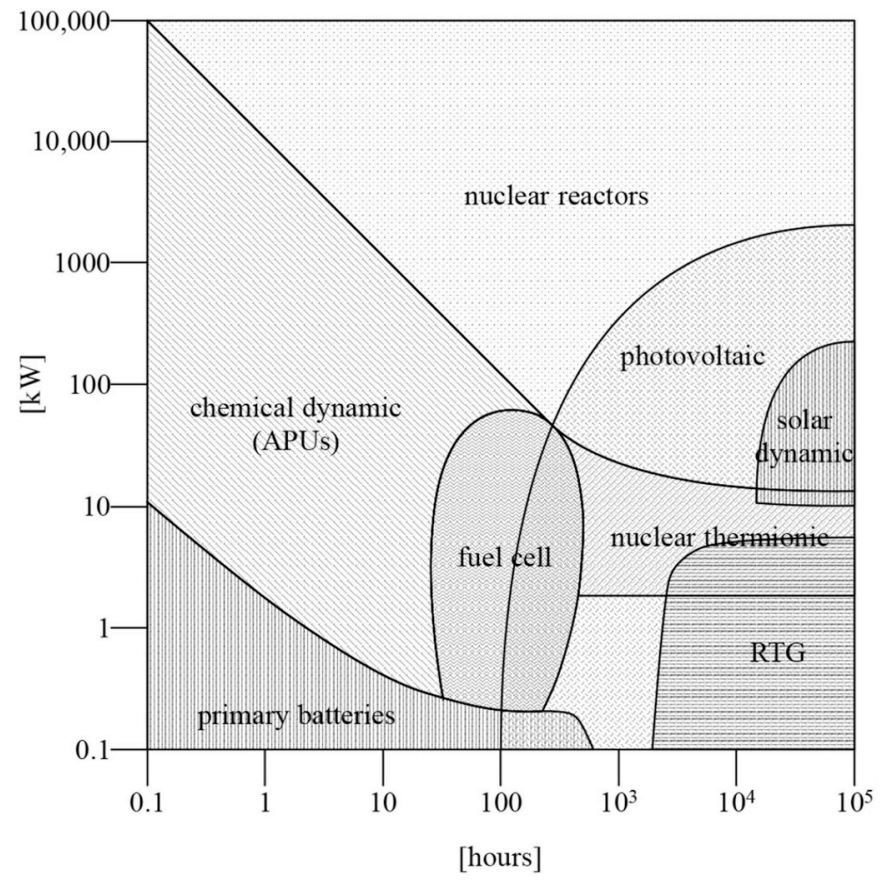

Fig. 3. This diagram describes the optimal option for power in space or on extraterrestrial bodies depending on the power that is required and the duration. This figure uses information from Human Spaceflight: Mission Analysis and Design [16] and Spacecraft Power Systems [34].

candidate. Furthermore, the construction of the base must rely exclusively on energy brought from Earth, excluding the possibility of using in-situ resourced energy for the first generation mission and therefore excluding the use of solar concentrators, which require to be installed. Finally, nuclear reactors add complexity to the mission for a small gain in mass compared to using RTGs, which have the advantage of being scalable to the requirements of the different phases. Therefore, RTGs have been selected as the power source used for the deployment of the first unit of the base and for the first crew generation mission. However, RTGs are only a temporary solution and over several crew generations or in the case of the expansion of the base, in-situ resources might want to be considered as replacement sources of power. Furthermore, the use of RTGs should be reevaluated according to developing technologies.

The main in-situ resourced options for power on Mars are geothermal power, solar concentrators or the use of naturally occurring methane sources [35]. Geothermal power is the most efficient in areas close to volcanic zones, which are located near the Equator and Southern regions and not in the North Polar regions so they cannot be considered as an option considering the choice of site.

Solar concentrators and methane sources can however be considered as possible options for powering a Mars North Polar base. Although the solar irradiance on Mars is only $586.2 \mathrm{~W} / \mathrm{m}^{2}$ [36] and the North Polar region only faces the Sun for half a Martian year, solar concentrators are more efficient than solar panels and can take advantage of the low gravity on the planet for their construction. Coupled with thermal storage, solar concentrators might be an option for providing the habitat with in-situ resourced power. Furthermore, methane could be collected at naturally occurring sources and burnt for energy. It is estimated that these sources are quite common, especially in the Northern latitudes and near the North Polar cap. Thorium reactors could also be considered [37]. In any case, in-situ testing must be performed in order to find an appropriate in-situ resourced energy, which could be solar concentrators, methane or any technology with currently low technology readiness level (TRL) for application on extraterrestrial bodies. 


\subsection{Air pressure}

The atmosphere on Mars is only $600 \mathrm{~N} / \mathrm{m}^{2}$ while the atmosphere on Earth is $101,325 \mathrm{~N} / \mathrm{m}^{2}$ at sea level. Because the habitat must mimic the conditions on Earth, it must be pressurized to a minimum of 0.8 bar, resulting in a pressure difference of $80,000 \mathrm{~Pa}$. These forces must be compensated by the habitat shell. The gravity on Mars is 0.375 times that on Earth, which implies that about three times more mass is required on Mars than on Earth to compensate an equal pressure difference. Materials with high tensile strength could furthermore compensate for a part of the pressure difference.

\subsection{Thermal control}

Although, due to the thin atmospheric density on Mars, convection and conduction are less important than radiation, the Mars base will lose heat that is required to maintain internal habitability for the crew. With careful thermal insulation design it should nevertheless be possible to ensure that the base produces more heat than it dissipates, providing excess energy that could be redirected to ice mining or for insitu resources processing, instead of being dissipated by radiators. Indeed, electrically powered equipment emits heat inside the base. This heat is tramsitted to the soil, the atmosphere and is radiated. The thermal insulation design must accommodate for possible large variations in the temperature of the soil, as it can warm up if in contact with heat-emitting sources such as power units [38], and for heat exchange with the atmosphere [39].

\subsection{Fire protection}

Because of the risk of fire, it is necessary to evaluate the fire safety capability gaps during fire safety studies and the choice of equipment for end-to-end detection/suppression/cleanup. Fire can be caused by short circuits, overheating of individual devices, electrostatic electricity, water or alcohol penetration into emergency oxygen regenerators, working on peroxide compounds of alkali metals and other sources. The main principle of fire protection is to control the temperature in the compartment, to ensure that the oxygen concentration does not exceed $40 \%$ in volume and the concentration of the hydrogen undesirable impurity should not be more than $2 \%$ of the volume $[40,41]$. Fire protection equipment uses:

- Automatic protection

- Galvanic isolation of power circuits

- Fire extinguishers based on the use of inert gases and neutral defoaming mixture (with low electrical conductivity)

- Depressurization of a compartment in which fire broke out

- Equipment for removing components of fire-extinguishing and formed combustion flues (for example aerosol filters and "vacuum cleaners")

In the near future, the unified, effective fire safety approach across small and large architecture elements will be used.

\section{System view}

Considering the different options identified, multiple main strategies are available. Three have been identified as being of particular interest for a Mars North Polar Research base. The technology behind all three options has been either demonstrated on Earth or has been simulated and its design is generally acknowledged but all require insitu testing:

\subsection{Ethylene}

The ethylene solution proposes to produce ethylene oxide propellant from Martian atmosphere and polar ice utilizing the Reverse Water-Gas Shift (RWGS) process. The advantage of ethylene is that the propellant is easy and safe to produce and can be produced entirely with in-situ available resources. The required oxygen can also be extracted from the atmosphere. Furthermore, the propellant can be used as radiation protection and in the production of different plastics, including polyethylene. Various objects including plastic membranes could be produced in-situ, while enabling repairs on the habitat. This technology still requires modifying a Reverse Water-Gas Shift (RWGS) reactor [42] using existing technologies and testing the technology on Earth.

\subsection{Ice}

In this solution, the chosen propellant is ALICE aluminum powder and ice solid propellant. Aluminum is available in Martian regolith and ice in the Polar caps. Ice, locally sourced at the Martian Pole, also has the advantage of being efficient at shielding from Cosmic Galactic Radiation (CGR). The propellant is considered a more environmentally friendly solid rocket fuel for terrestrial use, and so is under development and has been tested successfully during flight in 2009 [43]. Therefore, development within a decade of off-world technology is feasible, as it has been developed considering the challenges posed by an environment such as Mars.

\subsection{Methane}

The last option proposes to use methane oxide propellant. It is relatively straightforward to produce and the propellant can also be used as radiation protection. Production and testing of a Sabatier reactor producing methane has been realized [44].

In all three cases, ice must be mined in large quantities. This confirms that access to the North Pole of Mars is a particularly interesting feature for sustaining a long-term human presence.

\subsection{Selected strategy}

The strategy selected for the Mars Polar Research Base is a combination between the strategies based on ethylene and on ice. The proposed propellant is ethylene oxide. However, polyethylene fiber reinforced pykrete has been selected as radiation protection. This solution has three main advantages.

The first advantage is that polyethylene and other plastics such as polypropylene can be produced from ethylene with a pressurized heater. This implies that a wide variety of materials can be produced locally. For example, it would be possible to manufacture clothing, bags, insulation and tires among others [16]. This proves to be useful either for maintenance, variation of products or for an extension of the base in the future. This feature is consistent with an effort at enabling a long-term presence of humans on Mars.

The second advantage is that it is possible to manufacture membranes also. Materials derived from ethylene are the same materials from which membrane structures can be built [45]. This implies that not only could a crew have the possibility to do full repairs and maintenance on the membrane, which is likely to be required, but it is theoretically possible to produce more membranes that could serve as extensions for the base. For example, this could be useful if the base shall accommodate larger crews and/or to build greenhouses. Indeed, growing food on Mars requires large volumes of greenhouse, should this be proven to be efficient. Therefore, being able to add spaces to the base is also a key technology for enabling a long-term presence.

Finally, ethylene oxide is a relatively light but efficient propellant and it does therefore not require large quantities of hydrogen compared to other propellants. Because a crane system will be used for travels between Mars' orbit and its surface, being able to produce propellant easily is an advantage, especially when multiple trips between the 
surface of Mars and its orbit are necessary during a mission. The propellant will be contained in reservoirs located under the habitat, and can be used for refueling without compromising the integrity of the radiation protection or the polyethylene membrane retaining air pressure. This tank is only used when the crew is not occupying the base, as the crane vehicle must be fully tanked at all time during the crew's presence and refills after the crew's departure. When considering multiple simultaneous crew missions in a later stage, separate tanks can be installed further away if required. In both cases, because cryogenic ethylene can be hazardous, a risk assessment must be made in order to ensure its safe storage. For example, a safety distance and controlled leakage to avoid gas confinement must be accounted for.

As can be seen in Fig. 4, although the selected strategy is not closed loop, it takes advantage as much as possible of in-situ available resources and Fig. 5 describes the main equipment required for ensuring the availability of water, radiation protection, air pressure, propellant, plastics and air. Only food and energy need to be brought from Earth.

Finally, having identified a strategy for in-situ resource utilization (ISRU) and its advantages, such as mass minimization and the opportunity to further develop the base in the future with locally resourced materials, confirms the choice of a two phase mission scenario in which the habitat is sent and deployed before the crew even leaves Earth. The mission can therefore rely on Martian resources and the advantages linked to their utilization without compromising the safety of the crew.

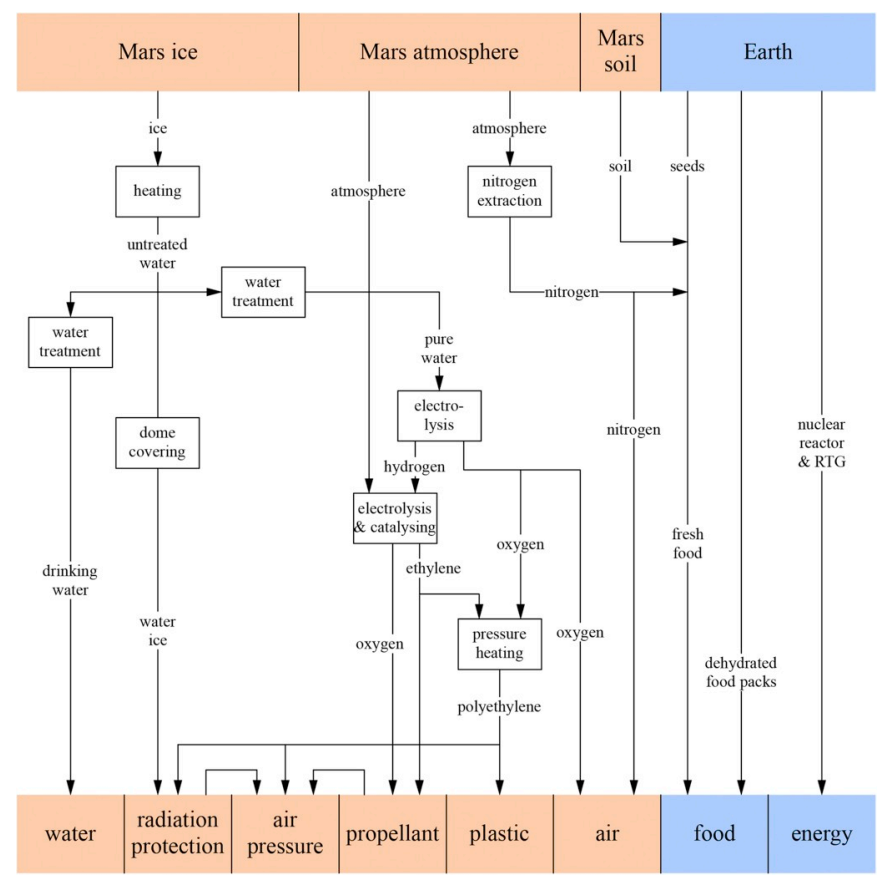

Fig. 4. This diagram describes a proposal of how to sustain a crew with life critical consumables and with materials necessary for the establishment and maintenance of a Mars base with a human crew. The origin of the elements used for the production of the material is also described in this diagram, allowing to identify what needs to be brought from Earth and what can be sourced in-situ.

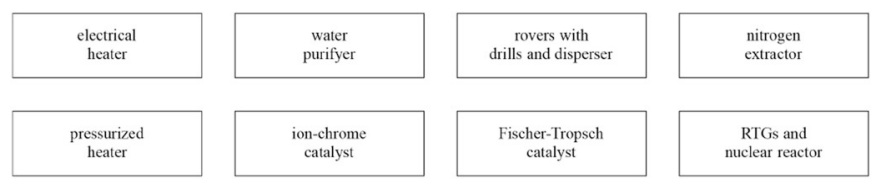

Fig. 5. This diagram gives a summary of the main equipment needed to ensure life support on Mars, in accordance with Fig. 5.

\section{Design proposal}

\subsection{Interplanetary transfer vehicle \& crane system}

Considering that a two-phase habitat deployment strategy has been selected and that one of the objectives of the missions is the preparation for human exploration, several interplanetary transfers and Mars orbitto-surface and surface-to-orbit transits are required. In order to reduce the mission mass, which is one of the most problematic aspects of crewed Mars missions considering the limited payload capacity in comparison with the required mass, a crane system is utilized for this mission. This system includes two crane vehicles and one interplanetary transfer vehicle for interplanetary transfers. The system's key features are modular capacity, reusablility and in-situ refuelability. Furthermore, the system is capable of precision landing. With the use of membranes, a small margin can be accommodated for [46].

The crane vehicle, illustrated in Fig. 6 , is a light structure with a replaceable $17.5 \mathrm{~m}$ inflatable heat shield, which the Inflatable Reentry Vehicle Experiment (IRVE-3) has demonstrated during a suborbital flight [47], a receptacle mechanism resembling the ISS docking system that can attach to any payload equipped with the appropriate plug and three thrusters that can be oriented so to perform rotations and translations during descent and ascent. The vehicle uses ethylene oxide as propellant and can therefore be refueled in-situ. Only one crane vehicle will be used for the first generation mission, the second one serving as redundancy and then during later mission.

The interplanetary transfer vehicle, illustrated in Fig. 7, is a vehicle made of three capsules and a central axis equipped with the plug to rendezvous with the crane vehicle. The capsules can be extended outwards of the structure upon landing and during interplanetary transfer and are shielded against SPE radiation. When transporting living organisms, the interplanetary transfer vehicle can be set into rotation around its own axis, allowing for artificial gravity in the deployed capsules.

The crane vehicle can be used for various Mars robotic or human missions and therefore is considered to be orbiting Mars and fully fueled at the begin of the mission, as it could also benefit robotic missions prior to the Mars Polar Research Mission. A proof-of-concept for landing payloads up to $899 \mathrm{~kg}$ for a Mars crane concept has been

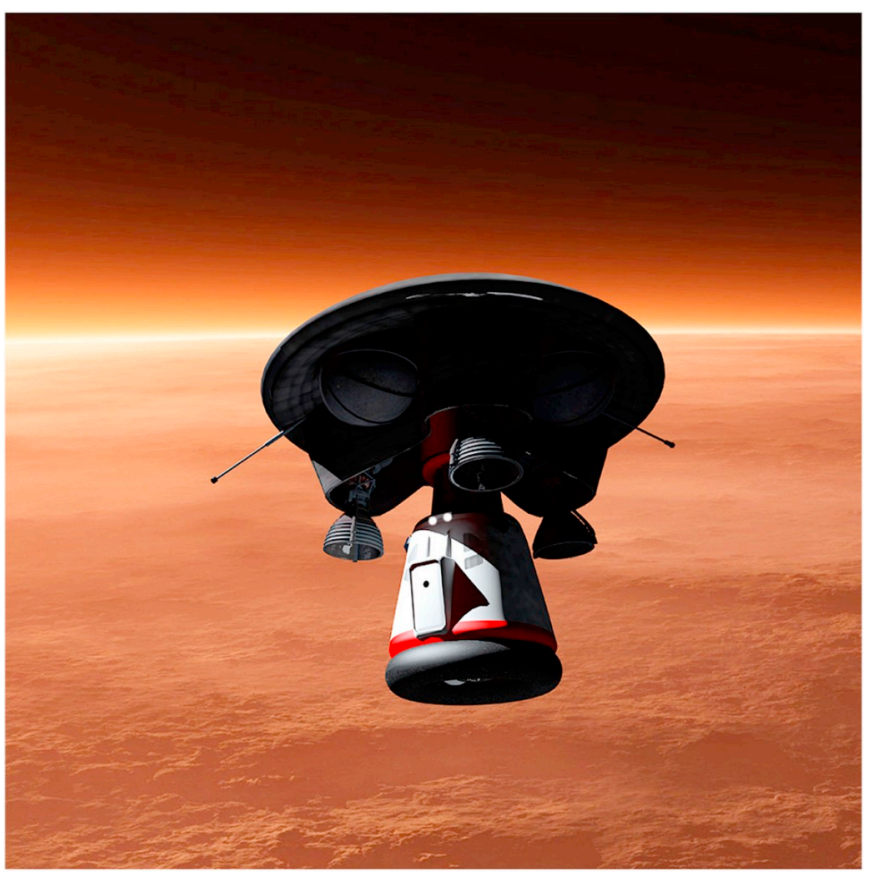

Fig. 6. Artist's view of a crane vehicle descending a crew capsule. 


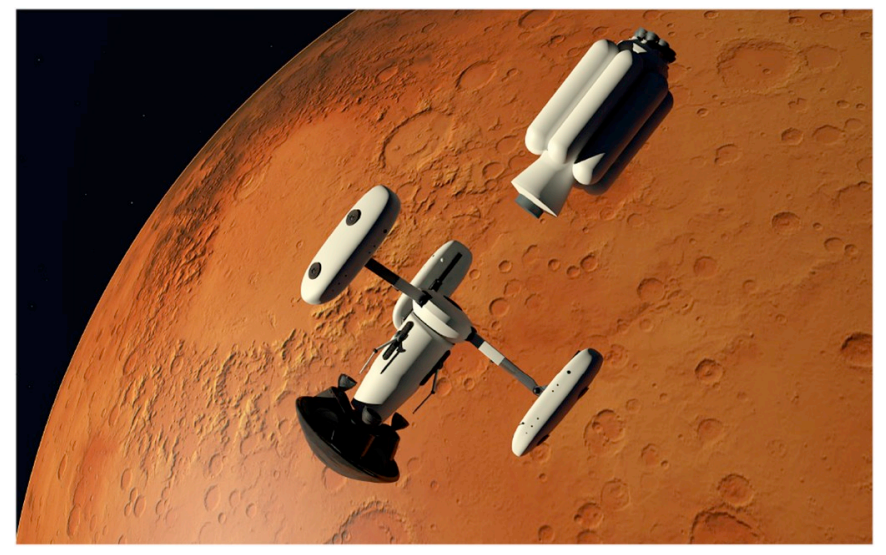

Fig. 7. Artist's view of an interplanetary transfer vehicle.

demonstrated by Sky Crane, which has deposited rover Curiosity on the surface of Mars in 2012 [48].

\subsection{Mars Polar Research Base}

The base must be sent to Mars utilizing launch systems with high Technology Readiness Level (TRL) and the rocket with the highest payload that is currently under development, which is the Space Launch System (SLS). This rocket's initial configuration is estimated to be able to deliver a payload of about 22 tons to Mars and up to 43 tons with evolved performance modifications [49]. Considering the estimated mass of the habitat of 110 tons, which has been calculated on Fig. 5, an Earth orbit or a Mars in-situ assembly is required. Furthermore, because most rockets have a fairing of about $5 \mathrm{~m}$ and the crew is sent during the second phase only, a deployable solution has been selected. Indeed, space has been considered to be a resource that can be found in-situ. As a consequence, the structure of the base is divided into three main elements: the central core, the capsules and the dome, which are described in Figs. 8 and 9. Plans of the base are described in Figs. 10 and 11.

The central core is a $12.5 \mathrm{~m}$ high deployable core, that fits into a $5 \mathrm{~m}$ in diameter circular fairing. The core includes three arms that can be extended outside of its initial perimeter, opening space inside its core for circulation and extending the first sealed membrane. The space added by the deployment of the arms allows to use the health center, the laboratory and the kitchen, as illustrated in Fig. 12, on the ground floor. The crew quarters can then be used on the first floor. The third floor, which has only partial height, is used for storage. The space defined by the first membrane is the minimal living space. The central core structure includes life support systems, bathrooms, the staircase and the circulation space.

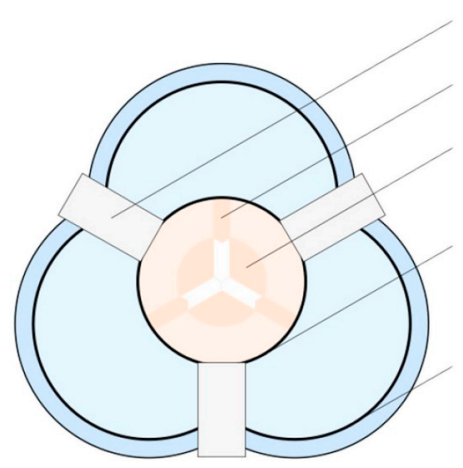

capsule

deployable arm mission \& life critical equipment sealed membrane ( $2^{\text {nd }}$ redundancy)

sealed membrane ( $1^{\text {st }}$ redundancy)

Fig. 8. Schematic plan

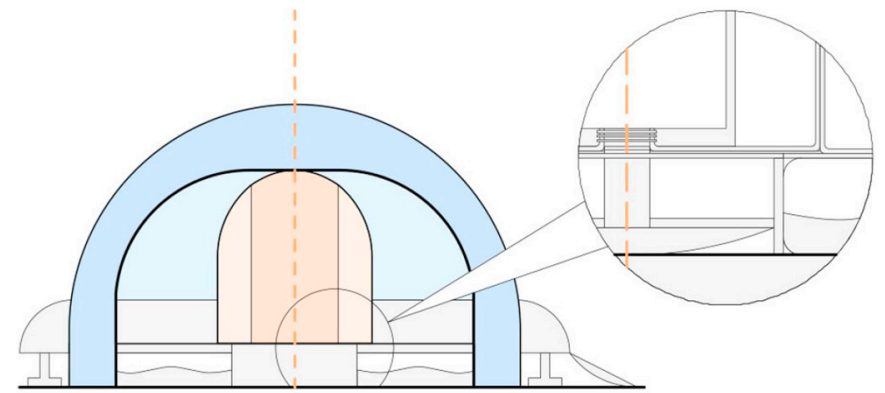

central core

minimal living space airlocks \& ISRU additional free space

pykrete protective dome circulation space
Fig. 9. Schematic section.

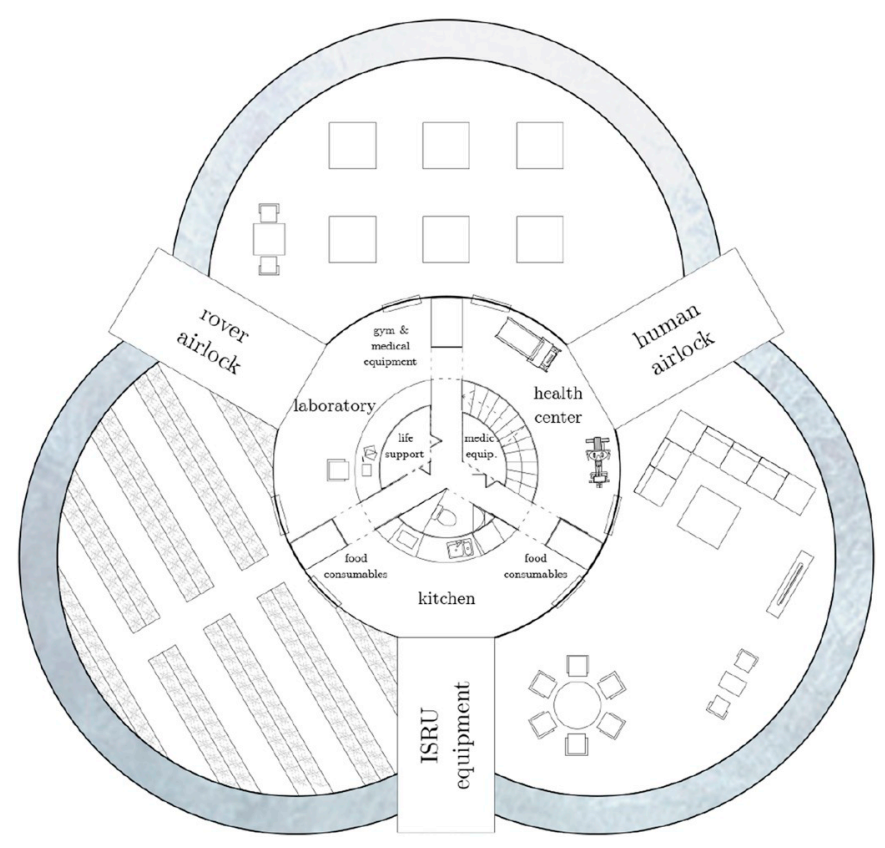

Fig. 10. Ground floor plan.

The capsules are disposed around the minimal living space and serve as human/rover airlocks and as IRSU equipment storage.

The dome is composed of water ice and polyethylene fibers pykrete, projected onto a second polyethylene sealed membrane and is about $3 \mathrm{~m}$ thick. The space defined between the first membrane and the second is the additional living space. It is divided into three compartments, which include the living room, a greenhouse and a laboratory extension, which can be used for storing ice samples. These can be accessed through doors in the membrane, which are airtight and must remain locked when not in use. The airlocks, opening towards the minimal living space and the exterior of the base, should also have the capacity to open into the additional living space, to ensure that the crew can reenter the minimal living space in case of a problem, without directly affecting the minimal living space. The storage tanks for water and ethylene are located under the ground floor level of the base and are protected at all times by the dome structure.

Besides providing the base with additional space, the dome also serves as a safety feature. Indeed, the dome protects the base against micrometeoroids and CGR. The polyethylene fibers included in the water ice 


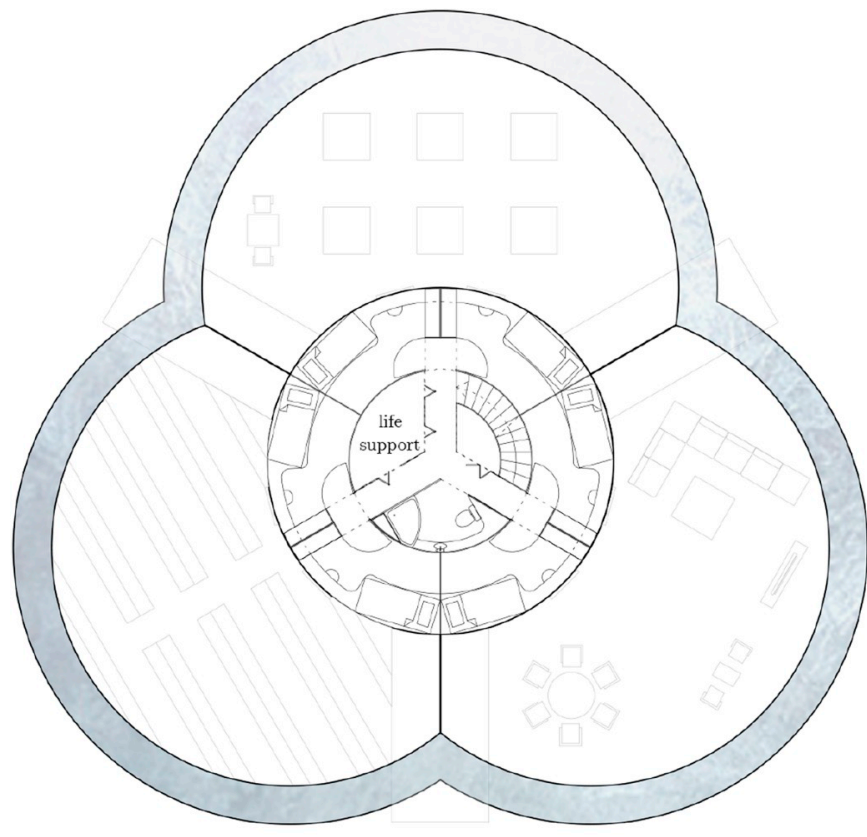

0

5 $10 \mathrm{~m}$

Fig. 11. First floor plan.

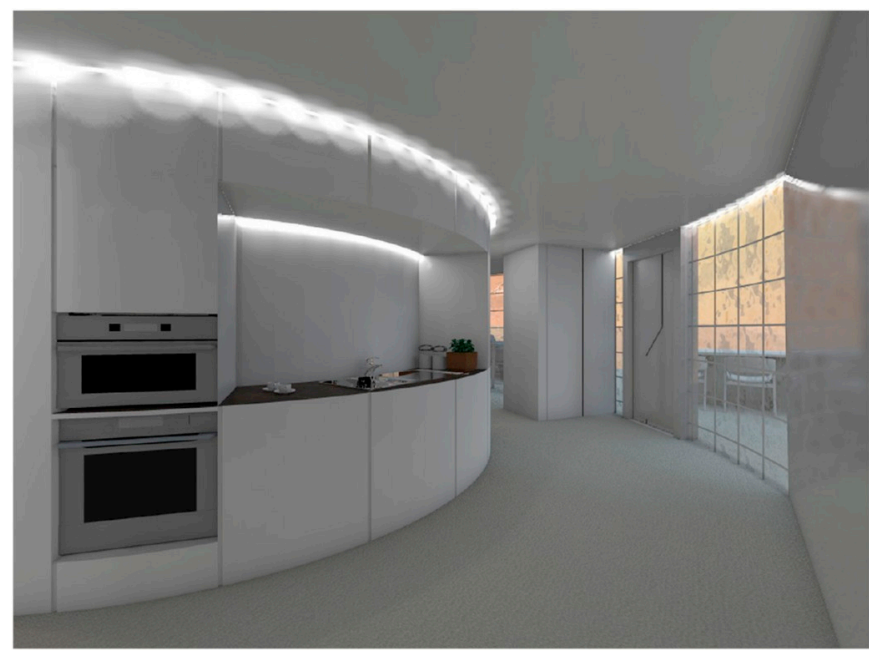

Fig. 12. Artist's view of the kitchen.

have the capacity to absorb shocks and also to work in traction, helping the polyethylene membrane to retain constant 0.8 bar inside the habitat. In case of a catastrophic event, a micro-meteoroid impact being the most likely, only one section of the dome should be damaged and lost. Considering that the capsules, which are located under the intersection of the dome compartments, and the central core contain the ISRU equipment and that polyethylene can be produced locally, reparations to the membranes and dome structure are conceivable.

Furthermore, all mission critical equipment must be protected at two levels of failure while all life critical equipment must be protected at three levels of failure. Therefore, in the case of total failure of the dome and exterior membrane, the minimal living space is capable of ensuring all mission and life critical features. In the case of failure of the interior membrane also, the mission must be aborted and the crew must take refuge in the airlocks, put their suits on and regain the crew capsule, which must be in the proximity of the habitat at all time and allow the crew to regain the orbiter, which stores life support equipment and enough food and water for a safe trip back to Earth.

The habitat can be duplicated and connected at the airlock level, in case of multiple crews visiting in the same time frame. Since polyethylene can be produced on Mars with in-situ sourced materials, more additional spaces can be built and covered with water ice and polyethylene fibers pykrete. The more habitats are built and connected, the higher the security of the crews will become.

\section{Scenario}

A two-phase habitat deployment strategy has been selected. In this section, the different steps will be described.

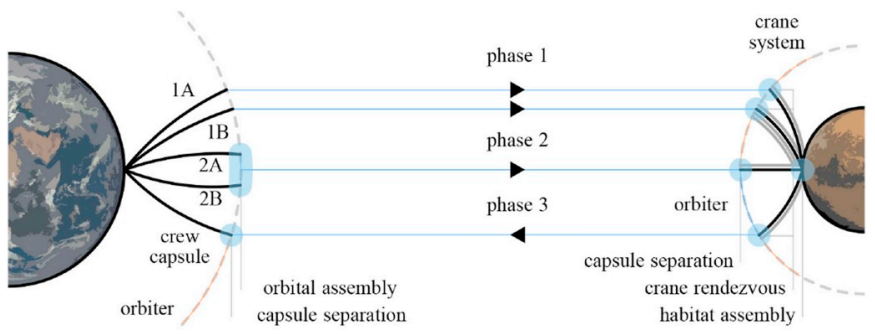

Fig. 13. Chronology (top to bottom) of the mission phases for the main scenario.

\subsection{Phase 1: habitat}

In the first phase, two SLS rockets with the Large Upper Stage (LUS) modification proposed by Boeing in 2013 [50] allowing a payload capacity estimated at 32.6 tons per rocket, are sent to Mars. This also corresponds to the payload capacity to Mars in NASA's 105 tons configuration proposed in its evolved performances [49]. One rocket contains the central core while the other contains the capsules. When in Mars orbit, the rocket containing the capsules first rendezvouses with the crane vehicle, which then descends the payload onto the surface of Mars. The capsules are kept folded behind the shield during the descent and before landing, the crane vehicle turns itself around and the capsules deploy horizontally and are deposited in their final position on the planet's surface. Since the ISRU equipment is contained in one of the capsules and the rovers in the two other, which are also the airlocks, the rovers start drilling for ice and bring it back to the ISRU equipment. Insitu resources will be transformed into ethylene and oxygen, which will be used for the crane vehicle to ascend back to orbit.

Once back in orbit, the crane rendezvouses with the second payload and also descends it onto the surface of Mars. The central core is deposited in its final position surrounded by the capsules. The crane's engines are angled outwards and the crane must rotate on its axis into a position ensuring the blast not to be directed towards the capsules or to damage the central core. Again, propellant will be produced from in-situ resources for the crane vehicle, allowing it to return into orbit.

Once the central core and the capsules are placed in-situ, the deployment of the base can begin. The first step is that of deploying the core arms and inflating the first membrane containing the minimal living space with in-situ produced air (oxygen and nitrogen). The second step is that of partially inflating the second membrane containing the additional space. In the third step, water with polyethylene fibers is propelled onto the dome membrane, which is gradually inflated up until 0.8 bar. The membrane structure is covered by a soft polyethylene structure on which the ice can form the dome. Ice is added until the dome is about $3 \mathrm{~m}$ thick and up to $6 \mathrm{~m}$ at its base. 


\subsection{Phase 2: crew}

In the second phase, two other LUS or 105 tons modified SLS rockets are launched with the crew aboard. An in-situ assembly is performed in Earth orbit in order to reduce the quantity of propellant required to send the payload to Mars, as both rocket structures can stay in Earth orbit. One rocket contains the central core while the other contains the capsules, forming the interplanetary transfer vehicle. During the trip to Mars, this vehicle is set in a rotational motion around its axis, creating artificial gravity in the deployed capsules (see Figs. 12-17).
When arrived in Mars orbit, the interplanetary transfer vehicle rendezvouses with the crane vehicle and the capsule containing the crew is descended onto the surface of Mars, landing on a site in walking distance of the base. The crew is then required to reach the habitat either with the assistance of the rovers or, should this not be possible, by foot. The rest of the interplanetary transfer vehicle remains in orbit during the duration of the mission.

Upon arrival of the crew in the base, the crew members can take possession of their personal quarters and are free to arrange and rearrange the additional spaces as convenient for them. In parallel, the

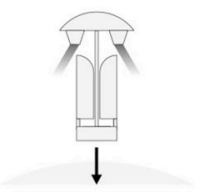

1. descent of crane \& capsules

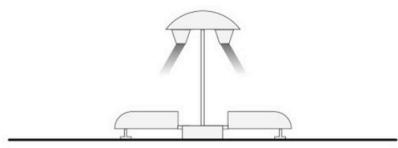

2. airlocks \& ISRU compartment deployment

5. crane refuelling

4. deployment of tank

$\&$ propellant production

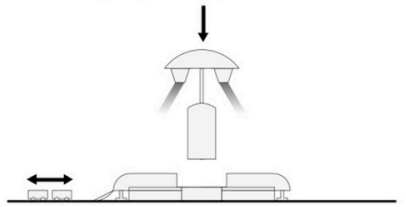

7. descent of crane \& core

with protective membrane

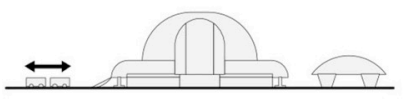

10. deployment of the second membrane

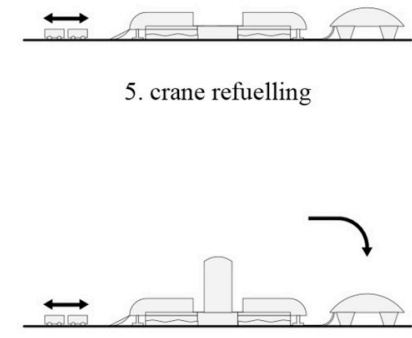

8. crane landing

\& crane refuelling

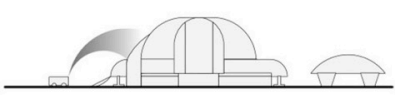

11. production of the ice dome \& propellant

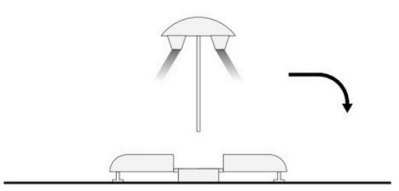

3. crane landing

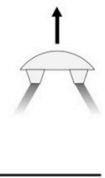

6. crane orbital ascent $\&$ propellant production

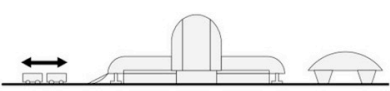

9. deployment of the core $\&$ first membrane

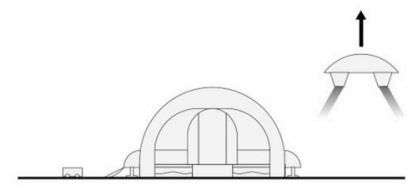

12. crane orbital ascent

Fig. 14. Conceptual schema of phase 1 - habitat deployment.

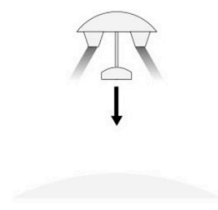

13. descent of crane \& crew capsule

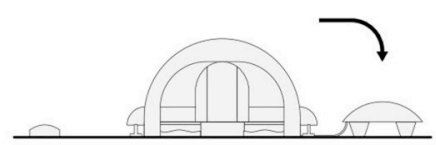

14. deployment of crew capsule \& crane refuelling

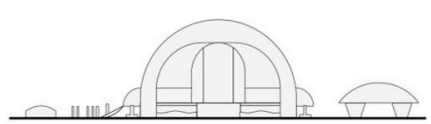

15. crew enters habitat $\&$ crane waits on Mars

Fig. 15. Conceptual schema of phase 2 - crew arrival.

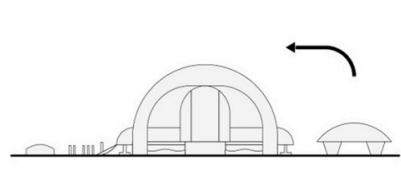

16. crew leaves habitat $\&$ enters crane
17. crane orbital ascent with crew

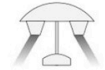

18. crew in orbit $\&$ rendezvous with orbiter
Fig. 16. Conceptual schema of phase 3 return to Earth. 
crane vehicle starts refueling after landing with propellant that has been produced before the landing of the crew as it is required that the crew must be able to evacuate and abandon the habitat at all time.

\subsection{Phase 3: return to Earth}

At the end of the 288-day surface mission, the crew returns to the orbiter using the crane vehicle. The crew must take with them a selection of ice samples that they have deemed as being of particular interest. The interplanetary transfer vehicle then leaves Mars' orbit and returns to Earth orbit. The crew capsule then lands on Earth with the crew. This is the end of the first generation mission.

\subsection{Next generations}

The base has been designed to be able to welcome several generations of crews. Given a large enough power storage system or a power source independent of light, crews could even consider staying all seasons in the base, in order to have a permanent human presence on Mars. The base has also been designed to serve as a starting point for an extended habitat system, considering that having access to Martian water reservoirs coupled with a life support system based on water enables larger crews to visit Mars. Indeed, in addition to the water for the crane system propellant, due to of the closed-loop life support system, water has to be resupplied only if the crew size is increased and for regular maintenance, as leaks are inevitable.

The base can be connected to multiples of the base at the airlocks. Furthermore, because of the possibility of producing polyethylene membranes in-situ, more additional space can be built at any time. Various objects that are non-essential to a first generation mission but can become an advantage when considering later missions or larger crews can be produced in polyethylene (with 3D printing technology for example) or brought from Earth. However, in order to be able to sustain crews of larger size or over longer periods of time, autonomy from Earth must be increased. Fig. 4 describing all consumables that can be produced in-situ or must be brought from Earth shows that food and energy are the limits to the base's autonomy. However, this can be improved over generations of crews visiting the habitat.

Indeed, in order to grow food, a greenhouse is required. Considering current research, it is estimated that it might be possible to grow food from Martian soil, if it is enriched with nitrogen [51]. Nitrogen can be extracted from Martian atmosphere by a nitrogen extractor, which is required for ensuring the nitrogen content in the habitat's air also. This would allow to bring only the seeds from Earth. Experiments should therefore be conducted either as secondary objectives or as main objective during later crew generations. As for power, the possibility of harvesting energy using in-situ solar concentrators coupled with thermal storage, naturally occurring methane or another option using in-situ resources material should be tested and possibly built over generations of crews, in order to allow the crew to grow in size.

\subsection{Trade-off scenarios}

Considering the low TRL that rockets capable of delivering over 30 tons of payload to Mars currently have, a trade-off scenario investigating the advantages of larger payload capacities is proposed. Indeed, considering that using SLS rockets with a 32.6 tons payload capacity to Mars, a Mars in-situ and an Earth orbit assembly are both required. Furthermore, Fig. 5 indicates that both the total payload for phase 1 and the total payload for phase 2 stand within a 60 ton margin. Therefore, if a rocket with a payload capacity of 60 tons to Mars was built, then the scenario could be simplified as described on Fig. 17. A descent capacity of 60 tons is therefore also admitted for the crane system.

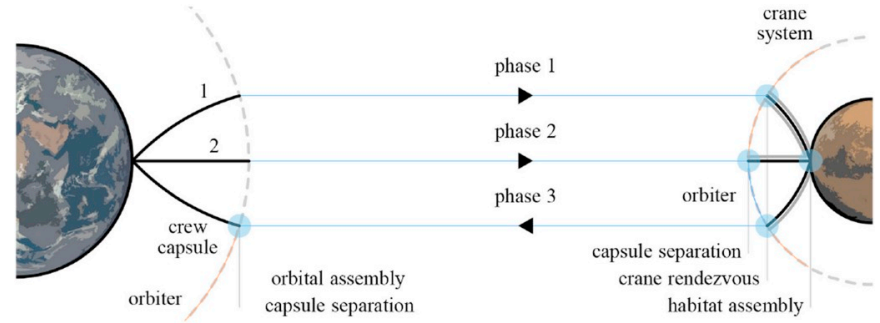

Fig. 17. Chronology (top to bottom) of the mission phases for the trade-off scenario.

Indeed, during the first phase, the interplanetary transfer vehicle is descended by the crane system in one descent only. Fig. 18 illustrates how the central core and the capsules are landed by the crane vehicle. The capsules are deployed shortly before touchdown. During the second phase, no Earth orbit assembly is required and the crew capsule is descended as in the main scenario.

\section{Budgets}

The payload mass, volume, power consumption and data of the Mars Polar Research Base has been estimated in Table 5. 10\% subsystem margin and $30 \%$ system margin have been included, which correspond to typical margins during pre-phase A [53], and maximum possible mass, volume, power consumption and data has been used for each subsystem. Equipment accommodating crews for Mars missions up to 700 days [16] have been included in both phase 1 and phase 2 . For each subsystem, the required redundancies have been included in the budget and integrated in the mission scenario design, as the orbiter can be used as a third level of redundancy.

The crane system however, has not been included in the budget but it has been estimated that the mass of one vehicle is approximatively 10 tons without fuel or payload, margins included. Although a concept using high TRL where possible is proposed, some key technologies present low TRL and as a consequence, the budget estimations may vary in accordance with future findings.

The total mass has been estimated at 110 tons, volume at $315 \mathrm{~m}^{3}$, power consumption at $160 \mathrm{~kW}$ and finally, the data has been estimated at 175,000 bits/day [52].

In the case where the payload capacity of rockets is maintained closely over 30 tons but the crane system descent payload capacity is increased to 60 tons, then both assemblies can be done in Earth orbit, simplifying the mission and reducing the propellant required for the interplanetary transfer.

\section{Discussion}

On a systems engineering level, two main areas in which technologies are to be developed have been identified. These are payload capacity and in-situ resource utilization. Payload capacity is especially important for the first crew generation as it is a mission and habitat design driving factor. When considering a long-term presence of humans on Mars, building materials and consumables become especially important however. Indeed, the more technologies in the areas of insitu resource utilization are developed and used, the lower the specifications become on payload capacity. The benefits become especially important over several crew generations.

\subsection{Payload capacity}

Currently, the payload capacity is limited to $16,800 \mathrm{~kg}$ with the Falcon Heavy rocket [54]. Considering that in Fig. 5, the total mass has 
Table 5

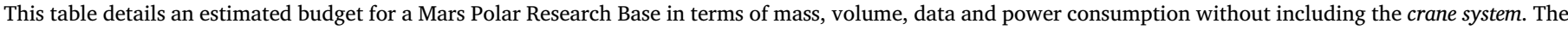

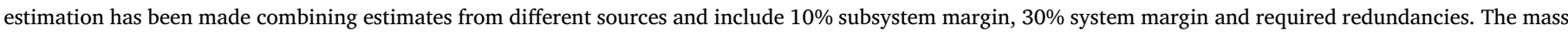

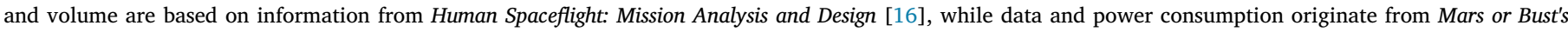
Martian Habitat Design [52].

\begin{tabular}{|c|c|c|c|c|c|c|c|}
\hline \multicolumn{4}{|l|}{ Phase 1} & \multicolumn{4}{|l|}{ Phase 2} \\
\hline Equipment & mass $[\mathrm{kg}]$ & volume $\left[\mathrm{m}^{3}\right]$ & power $[\mathrm{kW}]$ & Equipment & mass $[\mathrm{kg}]$ & volume $\left[\mathrm{m}^{3}\right]$ & power $[\mathrm{kW}]$ \\
\hline ISRU Equipment & 620 & 5.0 & 10.0 & Structure & 3400 & 3.5 & - \\
\hline Airlocks & 4950 & - & - & Galley and Food System & 745 & 4.0 & 6.25 \\
\hline Rovers & 3300 & 4.4 & 22.0 & Furniture & 975 & 2.5 & - \\
\hline Communications & 595 & 1.0 & 5.0 & Stowage & 660 & - & 0.05 \\
\hline Energy & 6080 & 6.2 & - & Exercise Facility & 160 & 0.2 & 0.15 \\
\hline $30 \%$ Margin & 4665 & 4.5 & 11.1 & Recreational Activities & 170 & 0.05 & 1.1 \\
\hline Total rocket $1 \mathrm{~A}$ & 20,210 & 21.6 & 48.1 & Housekeeping & 330 & 5.15 & 1.4 \\
\hline Structure & 3400 & 3.5 & - & Waste Collection System & 290 & 8.45 & 0.05 \\
\hline Furniture & 975 & 2.5 & - & Water System & 980 & 7.17 & 4.875 \\
\hline Usability & 5 & 0.05 & 0.2 & Water & 360 & 0.7 & - \\
\hline Galley and Food System & 745 & 4.0 & 6.25 & Food & 10,597 & 38.9 & - \\
\hline Recreational Activities & 170 & 0.05 & 1.1 & Clothing & 830 & 3.85 & 4.4 \\
\hline Personal Hygiene & 360 & 8.9 & 2.2 & Energy & 1775 & 1.8 & - \\
\hline Water Closet (WC) & 215 & 6.25 & 0.04 & $30 \%$ Margin & 6380 & 22.9 & 5.5 \\
\hline Clothing & 830 & 3.85 & 4.4 & Total rocket $2 \mathrm{~A}$ & 27,650 & 99.2 & 23.78 \\
\hline Crew Health Care & 1650 & 7.15 & 0.05 & Crew & 635 & 3.0 & - \\
\hline Exercise Facility & 160 & 0.2 & 0.15 & Crew Capsule & 6600 & 10.0 & - \\
\hline Stowage & 660 & - & 0.05 & Personal Hygiene & 360 & 8.9 & 2.2 \\
\hline Operational Supplies & 245 & 3.2 & 0.85 & Crew Health Care & 1650 & 7.15 & 0.05 \\
\hline Housekeeping & 330 & 5.15 & 1.4 & EVA & 540 & 5.5 & 2.5 \\
\hline Maintenance & 1980 & 8.25 & 2.2 & Communications & 595 & 1.0 & 5.0 \\
\hline Laboratory & 550 & 5.0 & 23.1 & Air System & 5850 & 8.3 & 3.9 \\
\hline EVA & 540 & 5.5 & 2.5 & Computers & 390 & 0.35 & 0.05 \\
\hline Computers & 390 & 0.35 & 0.05 & Thermal Control & 4255 & 12.6 & 0.7 \\
\hline Water System & 5 & 0.03 & 1.1 & Operational Supplies & 245 & 3.2 & 0.85 \\
\hline Food & 5855 & 21.5 & - & Maintenance & 1980 & 8.25 & 2.2 \\
\hline Air System & 5850 & 8.3 & 3.9 & Usability & 5 & 0.05 & 0.2 \\
\hline Waste System & 610 & 4.5 & 1.8 & $30 \%$ Margin & 6930 & 20.5 & 5.3 \\
\hline $30 \%$ Margin & 7657 & 29.5 & 15.40 & Total rocket $2 \mathrm{~B}$ & 30,035 & 88.8 & 22.95 \\
\hline Total rocket $1 \mathrm{~B}$ & 31,180 & 127.75 & 66.74 & Total phase 2 & 57,685 & 188.0 & 46.73 \\
\hline Total phase 1 & 51,390 & 149.35 & 114.84 & Total & 109,075 & 315.75 & 161.57 \\
\hline
\end{tabular}

been estimated at about $110,000 \mathrm{~kg}$, seven launches would be required. The price of a single launch stands at USD 90 million [54] and Earth orbit and Mars in-situ assemblies would be necessary, adding complexity to the mission and reducing the security for the crew. Furthermore, the central core's mass itself is estimated at $31,180 \mathrm{~kg}$, which implies that vehicles with a launch capacity inferior to this mass require more complex orbital assemblies and reduce the ability of taking advantage of deployable architectures. Therefore, both the payload capacity to Mars per launch should be increased and the use of in-situ resources should be maximized in order to minimize mass. Considering the mass estimations of this mission, we recommended to produce the LUS modification or 105 ton configuration evolved performance of for the SLS, which both have an estimated payload capacity of at least 33 tons. If possible, a rocket with a capacity of 60 tons payload could be produced, as 60 tons have been estimated to be required on one interplanetary transfer vehicle sending a crew to Mars. Furthermore, this technology would eliminate the need for the Mars in-situ and Earth orbit assemblies required with the modified SLS rocket.

It has been assumed that a crane system can be used for this mission and other crewed or robotic missions. This assumption has been made as several descents and ascents are required between Mars orbit and surface in this mission. Furthermore, the habitat has been designed with facilitating Mars surface missions for future generations of crews as a design criteria. The scenario has confirmed that, in this mission, the use of a crane system is required and we recommend the design, production and preparation of a crane system made of two crane vehicles, as this system would not only facilitate Mars surface robotic or crewed Mars surface missions but is a key technology in the establishment of the Mars Polar Research Base and when considering multi-generation crewed Mars surface missions. Considering the mission critical nature of the crane system, a separate study on the technology readiness level, feasibility of the crane system and it's design on a systems engineering level should be realized. A technology roadmap for this particular technology should also be proposed. Furthermore, validation missions are required before sending the Mars Polar Research Base to Mars. This also translates itself in the opportunity to test several technologies that are key in both the design of the crane system and the Mars Polar Research Base in-situ, such as the in-situ propellant production for example, during a preliminary phase. It should be noted that establishing a crane system in Mars' orbit is more complex than increasing the payload capacity to Mars.

Finally, because of the fairing, which is usually limited to under $6 \mathrm{~m}$ on most rockets, the volume which can be brought to Mars is limited both in total size and shape. But since space can be considered as an insitu found resource, deployable structures can be used to ensure sufficient space in the habitat. Deployable cores with extending arms can fit 


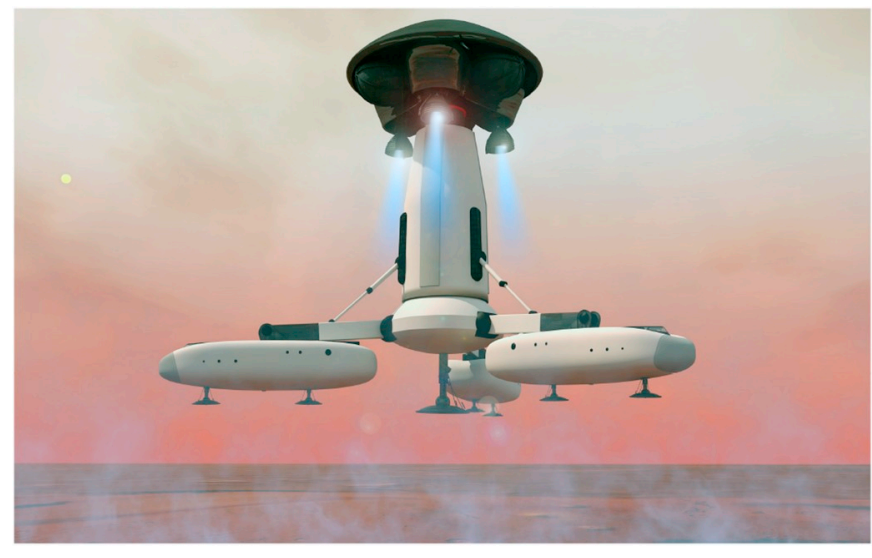

Fig. 18. Artist's view of the central core and the deployed capsules being deposited on Mars by the crane vehicle in the trade-off scenario.

into the fairing without wasting any space on empty volumes such as circulation space allowing access to instruments. This way, the use of the available fairing space becomes optimal. Furthermore, considering the difference in pressure between the habitat and Mars' atmosphere, inflatable structures are a great candidate for deploying additional spaces. Several plastics such as polyethylene and polypropylene are currently being evaluated as possible materials for membranes for planetary exploration missions [45]. In this mission, a deployable core coupled with two layers of inflatable membranes made of polyethylene membranes is proposed. The use of membranes facilitates the deployment of the core and this material has the advantage of being able to be produced in-situ from materials found on Mars. Having the capacity to add space to a habitat could prove especially useful on long-term or larger missions and could be used for greenhouses, if growing food on Mars proves to be feasible. Therefore, we recommend including deployable cores in the design of Mars missions with a human crew and developing in-situ producible membranes.

\subsection{Autonomy from Earth}

Since consumables must be resupplied regularly in order for humans to survive on Mars and that they account for a large part of the payload, they are a limiting factor to the presence of humans on Mars, especially when considering long-term missions.

As can be seen in Fig. 4, food and energy are the consumables required for the crew to survive and the mission to be implemented that necessarily need to be brought from Earth. Therefore, the development of technologies allowing for Mars grown food and harvested energy would not only facilitate future crewed missions but also allow for larger crews and longer missions. The consumables fraction of the payload increases with the length and size of a mission. Therefore, to facilitate missions or enable a larger variety of Mars missions with crew, the autonomy from Earth must be increased, the alternative being regular resupplying by rockets and the risks associated with the transits.

The difficulty with in-situ resource utilization and consumables lie in the fact that they are life critical technologies, and therefore need to be tested on Mars before a crew can rely on them. However, since insitu resource utilization technologies can be used for the construction of the habitat, therefore decreasing the mission mass, a two phase mission in which the habitat is constructed on Mars before the crew is even sent to the planet is preferable to a single phase mission. Indeed, since only partial testing can be done on Earth, this implies that the establishment of the base depends on hypothesis. Therefore, the mission scenario has to accommodate for a testing possibility during which the lives of the crew do not depend upon the results.

Food accounts for the largest part in consumables that need to be brought from Earth and is therefore a key technology for enabling the Mars Polar Research Base or any other crewed Mars mission to evolve. The first generation crew has to rely on dehydrated food brought from Earth and cannot rely on Mars grown food as it takes too much time to grow and the crew cannot rely on an untested life-critical technology. Therefore, technologies allowing food to grow on Mars should be tested rapidly. We recommend for an early crew generation to include the testing of in-situ food production technologies. Using a greenhouse to grow plants could potentially limit the requirement on resupply of consumables over several missions and also presents the advantage of having significant benefits for the crew's psychological well-being [55]. Considering this, a greenhouse has been included in the additional space in the design of the in the Mars Polar Research Base for the first generation crew. Several technologies are currently being developed for growing food in-situ and should be tested in-situ [56]. Possibly, locally found resources could even be used in the process of growing food, such as Martian regolith as soil or treated nitrogen extracted from Mars' atmosphere [51]. Seeds and other nutrients can be brought from Earth. In order to allow for in-situ testing and possibly reducing the quantity of material required to be brought from Earth to feed the crew, a greenhouse should be included in the design of the habitat.

Energy is required for Mars habitat. However, because Mars is too far from the Sun to be able to harvest solar energy using solar panels, alternative methods for collecting energy are necessary. Just as food, insitu collected energy cannot be utilized by a first generation crew, as energy is required to build the habitat. It is, however, also a key technology in enabling a long-term presence. Solar concentrators, locally available methane sourcing or other technologies could be implemented over several crew generations. Initial testing of candidate technologies could be done by the first generation crew as an auxiliary objective.

In addition to food and energy, autonomy from Earth concerning water and air made of oxygen and nitrogen should be developed as much as possible from the first crew generation on. A two-phase mission with the habitat constructed before the arrival of the crew allows to test technologies ensuring water and air and to confirm their success before even sending the crew to Mars.

Although a water cycle for six crew members can be maintained with less than $900 \mathrm{~kg}$, leakage and limited efficiency will, over time, imply that water must be added in-situ or more water brought from Earth. Because this mission is located near the North Pole and that water is therefore accessible, we propose that in the first phase of the mission, during the deployment of the habitat, the rovers will mine for water and the in-situ collected water will be processed into drinkable water before the crew travels to Mars. Therefore, autonomy from Earth in water could be tested and implemented by the first generation crew. Habitats in different locations might have to rely on different water sources. However, testing the possibility of supplying the base with water from the North Polar cap, if successful, could reinforce the hypothesis that the area near the Martian North Pole is a viable and safe option for a larger base with more crew members or even a Mars colony.

Air suffers from the same problems as water; leakage. Air must be replaced at a constant rate and therefore oxygen and nitrogen must be collected from the Martian environment. The Mars Polar Life Research Base proposes to test in-situ the production of oxygen via water electrolysis. It uses the mined ice to produce hydrogen that will be used in the production of ethylene and the oxygen can then be injected into the habitat. For the nitrogen, it can be noted that this element is present in the Martian atmosphere and therefore, there is a possibility of being absolutely independent of Earth concerning air by the first crew generation, considering that a nitrogen extractor can supply the habitat with nitrogen instead of bringing it in tanks. The extraction and treatment of nitrogen can furthermore also be used in experiments for growing food in-situ. 


\section{Conclusions}

Analysis of the mission requirements and the Martian context have established that a two phase mission should be selected because of the limited payload capacity to Mars. In fact, in a two phase mission during which the habitat is built during the first phase, in-situ resources can be taken advantage of. This reduces the mass budget of the mission and enables life and mission critical technologies to be tested and confirmed before the crew is sent to Mars.

In order to minimize the mass and take full advantage of the resources found at the Mars North Pole, an IRSU strategy allowing for equipment to serve for multiple purposes has been proposed. This strategy is based on mined ice water in combination with some elements from the atmosphere and others brought from Earth. The ice water is used as cover for the dome, to protect against CGR and micrometeoroids. Furthermore, the water ice can be transformed into ethylene using electrolysis and a Fischer-Tropsch catalyst. Ethylene can be used as an in-situ produced propellant (ISPP) with oxygen from the atmosphere and with a pressurized heater, polyethylene can be fabricated, which can be used for making membranes and plastic objects, allowing the crew to make repairs and to evolve the base.

Using these strategies, the mass, volume, power and data budgets have been estimated for the crewed Mars Polar Research Mission and are described in Table 6. From the strategy, the scenario and the budget estimation, several problems have been identified. Indeed, the low technology readiness level (TRL) of several technologies such as the payload capacity to Mars and in-situ resource utilization for consumables are factors limiting the possibilities for any Mars mission with a human crew, including close to the North Polar region. The repercussions are strong constraints on the mission architecture and on the habitat design. This is especially true in the case of a base that has the possibility of evolving and welcoming a long-term human presence on Mars.

Considering that the payload capacity has been identified as a key technology to be developed, several recommendations have been made as a result of this analysis. The first is to develop rockets with payload capacities of about 33 tons, which is equivalent to Boeing's proposition of a LUS modification or NASA's 105 tons evolved performance SLS modification. Alternatively, rockets with a capacity of about 60 tons could be developed, as it has been estimated that this is the minimum payload considering high TRL that is required on one interplanetary transfer vehicle for the crew. It is also consistent with the mass of the habitat, which is about 50 tons. The second is to design and build a crane system using in-situ produced propellant (ISPP), which can ensure the trips between Mars' orbit and surface for crewed and robotic exploration mission. Indeed, a crane system has the potential to enable Mars missions with crew, especially when considering long-term presence of humans, and facilitating robotic missions. The third recommendation is to consider volume as an in-situ available resource and therefore to include deployable structures considering the limited available fairing. In the studied scenario, a combination between a deployable core and in-situ produced membranes from locally available materials has been shown to be an efficient strategy.

Limited autonomy from Earth regarding consumables has been identified as a key technology presenting low TRL. Autonomy from

Table 6

This table is a summary of Table 5 and shows the total estimation for mass, volume, energy and data for a Mars Polar Research Mission.

\begin{tabular}{ll}
\hline Metric & Total \\
\hline mass $[\mathrm{kg}]$ & 110,00 \\
volume $\left[\mathrm{m}^{3}\right]$ & 315 \\
power consumption $[\mathrm{kW}]$ & 160 \\
data [bits/day] & 175,000 \\
\hline
\end{tabular}

Earth is necessary for enabling larger crews or longer missions, which is consistent with the objective of a long-term presence on Mars. Considering this, we recommend to include the possibility of using these technologies in the base's design and to include their testing as soon as the first crew generation. The technologies allowing for water, oxygen and nitrogen to be produced in-situ can be tested in the first phase, before the departure of the first generation crew. The technologies with lower TRL, which are those allowing for food and energy to be produced in-situ, should be tested during the first mission including a human crew. Therefore it has been recommended to include a nitrogen extractor, a fully equipped greenhouse capable of testing different methods of food growth and various prototypes, such as solar dynamic, methane sourcing technologies and other candidates, allowing to test in-situ energy production in the habitat's design.

Finally, this mission design has concluded that the Martian North Pole could be a viable candidate for supporting temporary crews and a long-term presence on Mars, as ISRU strategies using water ice could theoretically be implemented. This mission design has also concluded that it is realistic to consider that a first crewed base on Mars at the North Pole should already include all the design features for preparing a long-term presence on Mars, as it presents to be an optimal strategy minimizing the mass budget over several crew generations. Technologies enabling autonomy from Earth regarding consumables should be tested as soon as the first crew generation, as the results will enable the Mars Polar Research Mission to evolve and other possible crewed missions to Mars to be able to rely on in-situ tested life-support systems.

Overall, the recommendations resulting from the design of the Mars Polar Research Mission are consistent with NASA's Technology Roadmaps, which have established a calendar for developing the technologies necessary for a Mars crewed mission to be ready in the late 2020s or 2030s. Indeed, increasing the payload capacity (TA 1.1) [57], proposing solutions for evolving habitats (TA 7.4.2) [13], developing technologies allowing for in-situ entry, descent, and landing systems (TA 9) [58] have been included in the roadmap. In-situ resource utilization has also been identified (TA 7.1) [13], especially when considering consumables required for life support. This article has identified specific technologies in each of these areas and recommends the further analysis and possible development of the proposed technologies.

\section{Declarations of interest}

None.

\section{Funding}

This research did not receive any specific grant from funding agencies in the public, commercial, or not-for-profit sectors.

\section{Acknowledgments}

We would like to take this opportunity to thank Muriel Richard from the Space Engineering Center (eSpace) at the Ecole Polytechnique Fédérale de Lausanne (EPFL) for her support. We would also like to thank Dr. Olga Bannova who has encouraged and fostered this project and its publication, Dr. Barbara Imhof, Waltraut Hoheneder and Dr. Susmita Mohanty from Liquifer Systems Group, who have supported us and provided us with valuable resources. Furthermore, we would also like to thank Peter Zurbrügg and Alain Nussbaumer, who are teaching the class "Living on Mars" at the Ecole Polytechnique Fédérale de Lausanne (EPFL), Suren Erkman from the faculty for Geosciences and Environment at the University of Lausanne (UNIL) and Théodore Besson from Earth Space Technical Ecosystems Enterprises (ESTEE). 


\section{References}

[1] NASA, Nasa telescope reveals largest batch of Earth-size, habitable-zone planets around single star, https://www.nasa.gov/press-release/nasa-telescope-revealslargest-batch-of-earth-size-habitable-zone-planets-around, (2017), Accessed date: 22 August 2017

[2] E. Petigura, A. Howard, G. Marcy, Prevalence of Earth-size planets orbiting Sun-like stars, Proc. Natl. Acad. Sci. Unit. States Am. 110 (48) (2013) 19273-19278.

[3] C. Sagan, J. Lederberg, The prospects for life on Mars: a pre-Viking assessment, Icarus 28 (2) (1976) 291-300.

[4] B.M. Jakosky, C.B. Farmer, The seasonal and global behavior of water vapor in the Mars atmosphere: complete global results of the Viking atmospheric water detector experiment, J. Geophys. Res. 87 (B4) (1982) 2999-3019.

[5] F.J. Martin-Torres, M.-P. Zorzano, P. Valentn-Serrano, A.-M. Harri, M. Genzer, O. Kemppinen, E.G. Rivera-Valentin, I. Jun, J. Wray, M.B. Madsen, W. Goetz, A.S. McEwen, C. Hardgrove, N. Renno, V.F. Chevrier, M. Mischna, R. NavarroGonzlez, J. Martnez-Fras, P. Conrad, T. McConnochie, C. Cockell, G. Berger, A.R. Vasavada, D. Sumner, D. Vaniman, Transient liquid water and water activity at Gale crater on Mars, Nat. Geosci. 8 (2015) 357-361.

[6] H. Klein, The Viking biological investigation: general aspects, J. Geophys. Res. 82 (28) (1977) 4677-4680.

[7] H. Klein, The Viking mission and the search for life on Mars, Rev. Geophys. 17 (7) (1979) 1655-1662.

[8] H. Lammer, E. Chassefire, A. Karatekin, P. Morschhauser, O. Niles, P. Mousis, U. Odert, D. Mstl, V. Breuer, M. Dehant, H. Grott, E. Grller, L.-B.-S. Hauber, Pham, Outgassing history and escape of the martian atmosphere and water inventory, Space Sci. Rev. 174 (14) (2013) 113-154.

[9] M. E. P. A. G. (MEPAG), Mars Science Goals, Objectives, Investigations, and Priorities: 2015 Active Version, National Aeronautics and Space Administration, 2015.

[10] M. Peplow, Martian Pole reveals ice age cycles, http://www.nature.com/news/ 2005/050221/full/news050221-14.html, (2005) , Accessed date: 12 February 2018.

[11] G.L. Villanueva, M.J. Mumma, R.E. Novak, H.U. Kufl, P. Hartogh, T. Encrenaz, A. Tokunaga, A. Khayat, M.D. Smith, Strong water isotopic anomalies in the mar tian atmosphere: Probing current and ancient reservoirs, Science 348 (6231) (2015) 218-221.

[12] U. L. A. (ULA), Delta IV, https://www.ulalaunch.com/rockets/delta-iv, (2017), Accessed date: 8 February 2018.

[13] NASA, Nasa Technology Roadmaps; TA 7: Human exploration destination systems, https://www.nasa.gov/offices/oct/home/roadmaps/index.html, (2015) , Accessed date: 2 May 2018

[14] A.S. Howe, B. Sherwood, Out of This World: the New Field of Space Architecture, first ed., American Institute of Aeronautics and Astronautics, 2009.

[15] T. Owen, K. Biemann, D. Rushneck, J. Biller, D. Howarth, A. Lafleur, The composition of the atmosphere at the surface of Mars, J. Geophys. Res. 82 (28) (1977) $4635-4639$

[16] J. Wiley, W. Larson, L. Pranke, Human Spaceflight: Mission Analysis and Design, first ed., McGraw-Hill Companies, 1999.

[17] M. Perchonok, C. Bourland, Nasa food systems: past, present, and future, Nutrition 18 (10) (2002) 913-920.

[18] C. Leonardi, Modular aircraft clip-air, http://clipair.epfl.ch/, (2018) , Accessed date: 6 February 2018.

[19] D. Clark, In-situ propellant production on Mars: a sabatier/electrolysis demonstration, Proceedings of the 33rd Joint Propulsion Conference and Exhibit, American Institute of Aeronautics and Astronautics, Seattle, USA, 1997.

[20] N.Q. Minh, B.W. Chung, R. Doshi, G.R. Lear, K. Montgomery, E.T. Ong, Fabrication and performance of zirconia electrolysis cells for carbon dioxide Reduction for Mars In-situ Resource Utilization Applications, (1999).

[21] A.C. Muscatello, E. Santiago-Maldonado, Mars in situ resource utilization technology evaluation, 50th AIAA Aerospace Sciences Meeting Including the New Horizons Forum and Aerospace Exposition, American Institute of Aeronautics and Astronautics, Nashville, USA, 2012

[22] J. Yoshihara, C.T. Campbell, Methanol synthesis and reverse watergas shift kinetics over Cu(110) model catalysts: structural sensitivity, J. Catal. 161 (2) (1996) 776-782.

[23] R. Zubrin, B. Frankie, T. Kito, Mars in-situ resource utilization based on the reverse water gas shift - experiments and mission applications, 33rd Joint Propulsion Conference and Exhibit, American Institute of Aeronautics and Astronautics, Seattle, USA, 1997.

[24] A. Risha, T.L. Connell, R.A. Yetter, V. Yang, T.D. Wood, M.A. Pfeil, T.L. Pourpoint, S.F. Son, Aluminum-ice (ALICE) propellants for hydrogen generation and propulsion, 45th Joint Propulsion Conference and Exhibit, American Institute of Aeronautics and Astronautics, Denver, USA, 2009.

[25] T.L. Pourpoint, T.D. Wood, M.A. Pfeil, J. Tsohas, S.F. Son, Feasibility study and demonstration of an aluminum and ice solid propellant, Int. J. Aero. Eng. 2012 (2012) 87407611 pages http://dx.doi.org/10.1155/2012/874076.

[26] D. M. Hassler, C. Zeitlin, R. F. Wimmer-Schweingruber, B. Ehresmann, S. Rafkin, J. L. Eigenbrode, D. E. Brinza, G. Weigle, S. Bttcher, E. Bhm, S. Burmeister, J. Guo, J. Khler, C. Martin, G. Reitz, F. A. Cucinotta, M.-H. Kim, D. Grinspoon, M. A. Bullock, A. Posner, J. Gmez-Elvira, A. Vasavada, J. P. Grotzinger, Mars' surface radiation environment measured with the Mars Science Laboratory's Curiosity rover, Science 343(6169).
[27] D. Rapp, Radiation effects and shielding requirements in human missions to the Moon and Mars, MARS, Int. J. Mars Sci. Explorat. 2 (2006) 46-71.

[28] J.W. Wilson, J. Miller, A. Konradi, A. Cucinotta, Shielding strategies for human space exploration, National Aeronautics and Space Administration, 1997.

[29] T.C. Slaba, C.J. Mertens, S.R. Blattnig, Radiation shielding optimization on Mars, National Aeronautics and Space Administration, 2013.

[30] L.C. Simonsen, J.E. Nealy, Radiation protection for human missions to the Moon and Mars, National Aeronautics and Space Administration, 1991.

[31] S. Guatelli, B. Mascialino, P. Nieminen, M. Pia, Radiation shielding simulation for interplanetary manned missions, 10th Topical Seminar on Innovative Particle and Radiation Detectors, Siena, Italy, 2006.

[32] M. Langford, K. Johnson-Throop, What is space radiation? https://srag.jsc.nasa. gov/spaceradiation/What/What.cfm, (2016), Accessed date: 31 August 2017.

[33] J.W. Wilson, F.A. Cucinottaa, J.L. Shinna, L.C. Simonsena, R.R. Dubeyb, W.R. Jordanb, T.D. Jonesc, C.K. Changd, M.Y. Kime, Shielding from solar particle event exposures in deep space, Radiat. Meas. 30 (3) (1999) 361-382.

[34] D.W. Miller, J. Keesee, Spacecraft power systems, https://ocw.mit.edu/, (2016), Accessed date: 30 August 2017.

[35] M. Mumma, G. Villanueva, R. Novak, T. Hewagama, B. Bonev, M. DiSanti, A. Mandell, M. Smith, Strong release of methane on Mars in northern summer 2003, Science 323 (5917) (2009) 1041-1045.

[36] D.R. Williams, Mars fact sheet, https://nssdc.gsfc.nasa.gov/planetary/factsheet/ marsfact.html, (2016) , Accessed date: 2 October 2017.

[37] R. Smith, Liquid fluorine thorium reactors on mars, http://citeseerx.ist.psu.edu/ viewdoc/download?doi =10.1.1.662.5256\&rep = rep1\&type = pdf, (2012) Accessed date: 2 May 2017.

[38] E. Farias, M. Redmond, P. Bhandari, J. Kempenaar, K. Novak, Thermal modeling of Mars ground for surface missions, 47th International Conference on Environmental Systems, Texas Digital Library, Charleston, USA, 2017.

[39] P. Bhandari, K. Anderson, Cfd analysis for assessing the effect of wind on the thermal control of the Mars Science Laboratory Curiosity rover, 43rd International Conference on Environmental Systems, American Institute for Aeronautics and Astronautics, Vail, USA, 2013.

[40] B.A. Adamovich, M.G. Akopov, A.V. Vestnyak, A.M. Matveenko, Testing and Exploitation of Space Life Support Systems, (2003), p. 159.

[41] D.R. Williams, ECLSS and fire safety, https://www.nasa.gov/site/default/files/ atoms/file/7Qgatenseclssfiresafetytagged.pdf , Accessed date: 6 October 2017.

[42] J. Holladay, K. Brooks, P. Humble, J. Hu, T. Simon, Compact reverse water-gas-shift reactor for extraterrestrial in situ resource utilization, J. Propul. Power 24 (3) (2008) 578-582.

[43] D. Kittell, T. Pourpoint, L. Groven, S. Son, Further development of an aluminum and water solid rocket propellant, J. Propul. Power 24 (3) (2008) 578-582.

[44] R. Cusick, Space station prototype sabatier reactor design verification testing, Intersociety Conference on Environmental Systems, National Aeronautics and Space Administration, Seattle, USA, 1974.

[45] T. Sinn, O. Doule, Inflatable structures for Mars base 10, 42nd International Conference on Environmental Systems, American Institute for Aeronautics and Astronautics, San Diego, USA, 2012.

[46] L. Blackmore, Autonomous precision landing of space rockets, https://www.nae edu/19582/Bridge/164237/164334.aspx, (2016), Accessed date: 2 May 2018.

[47] D. Lichodziejewski, C. Kelley, B. Tutt, D. Jurewicz, G. Brown, B. Gilles, D. Barber, R. Dillman, C. Player, Design and testing of the inflatable aeroshell for the IRVE-3 flight experiment, 53rd AIAA/ASME/ASCE/AHS/ASC Structures, Structural Dynamics and Materials Conference, American Institute for Aeronautics and Astronautics, Honolulu, USA, 2012.

[48] R. Kornfeld, R. Prakash, A. Devereaux, M. Greco, C. Harmon, D. Kipp, Verification and validation of the Mars Science Laboratory/Curiosity rover entry, descent, and landing system, J. Spacecraft Rockets 51 (4) (2014) 1251-1269.

[49] S. Creech, Nasas space launch system: A capability for deep space exploration, https:// www.nasa.gov/sites/default/files/files/Creech_SLS_Deep_Space.pdf, (2014), Accessed date: 12 February 2018.

[50] E. Kyle, Space launch report, http://www.spacelaunchreport.com/sls0.html, (2017) , Accessed date: 15 February 2018.

[51] W. Larson, P. McQuade, Human Spaceflight: Mission Analysis and Design, McGrawHill Education - Europe, 2007.

[52] I. Mars or Bust, Martian Habitat Design, first ed., University of Colorado, 2003.

[53] G. S. F. Center, Rules for the design, development, verification, and operation of flight systems, https://www.goes-r.gov/syseng/docs/GSFC_STD_1000.pdf, (2009), Accessed date: 2 May 2018.

[54] SpaceX, Falcon Heavy, http://www.spacex.com/falcon-heavy, (2017) , Accessed date: 2 September 2017

[55] B. Imhof, A.-M. Rüede, KNAUF Mars Competitions Requirements, Liquifer Systems Group, 2014.

[56] T. Ivanova, P. Kostov, S. Sapunova, I. Dandolov, F. Salisbury, G. Bingham, V. Sytchov, M. Levinskikh, I. Podolski, D. Bubenheim, G. Jahns, Six-month space greenhouse experiments a step to creation of future biological life support systems, Acta Astronaut. 42 (1-8) (1998) 11-23.

[57] NASA, Nasa Technology Roadmaps; TA 1: Launch propulsion systems, https:// www.nasa.gov/offices/oct/home/roadmaps/index.html, (2015), Accessed date: 2 May 2018.

[58] NASA, Nasa Technology Roadmaps; TA 9: Entry, descent, and landing systems, https://www.nasa.gov/offices/oct/home/roadmaps/index.html, (2015), Accessed date: 2 May 2018. 


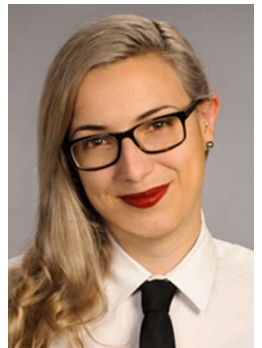

Anne-Marlene Rüede is a student at the Swiss Polytechnic Federal Institute in Lausanne (EPFL). She is majoring in Architecture and Space Technologies with the objective of becoming a space and extreme environments architect.

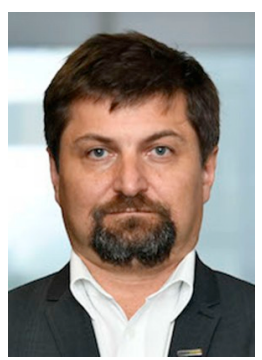

Dr Anton B. Ivanov has been recently (2017) appointed as the Director of the Space Center at the Skolkovo Institute of Science and Technology in Moscow, Russia. This work was initiated when Dr. Ivanov was Scientist with the EPFL Space Center. He is currently the project manager for the CubETH CubeSat project, study leader for the CHEOPS satellite and was responsible for the Minor in Space Technologies EPFL. After receiving his PhD in Planetary Science from Caltech in 2000, Dr Ivanov joined the Jet Propulsion Laboratory to contribute to Mars Global Surveyor, Mars Odyssey, Mars Express and Mars Science Laboratory projects. From 2007 until 2017, Dr. Ivanov was a scientist with the EPFL Space Center and the Swiss Space Center.

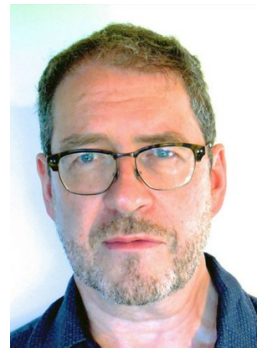

Claudio Leonardi is the head of the Clip-Air project at the Swiss Polytechnic Federal Institute in Lausanne (EPFL) since 2009, and is in charge of the architecture, the structure and the management of the project. He also manages coordination and development in the fields covered by the Clip-Air project: transportation, modular logistics, mechanics, structure, architecture. Claudio Leonardi has already been involved in a number of major projects, including Solar Impulse. He has also collaborated with Yves Rossy aka Jetman.

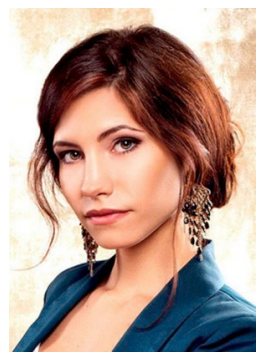

Tatiana Volkova is an aerospace engineer \& space architect and graduated from Bauman Moscow Technical University and Ecole Polytechnique Paris. Tatiana's personal goal is to drive the growth of innovation in the field of architecture in extreme conditions and is passionate about habitat design overall efficiency. She is currently conducting her $\mathrm{PhD}$ research at the Swiss Polytechnic Federal Institute in Lausanne (EPFL) in the field of architecture in the extreme environments. 